This time it's personal: reappraisal after acquired brain injury

Rowlands, Leanne; Coetzer, Rudi; Turnbull, Oliver

\title{
Cognition and Emotion
}

\author{
DOI: \\ 10.1080/02699931.2020.1839384
}

Published: 17/02/2021

Peer reviewed version

Cyswllt i'r cyhoeddiad / Link to publication

Dyfyniad o'r fersiwn a gyhoeddwyd / Citation for published version (APA):

Rowlands, L., Coetzer, R., \& Turnbull, O. (2021). This time it's personal: reappraisal after acquired brain injury. Cognition and Emotion, 35(2), 305-323.

https://doi.org/10.1080/02699931.2020.1839384

\footnotetext{
Hawliau Cyffredinol / General rights

Copyright and moral rights for the publications made accessible in the public portal are retained by the authors and/or other copyright owners and it is a condition of accessing publications that users recognise and abide by the legal requirements associated with these rights.

- Users may download and print one copy of any publication from the public portal for the purpose of private study or research.

- You may not further distribute the material or use it for any profit-making activity or commercial gain

- You may freely distribute the URL identifying the publication in the public portal ?
}

Take down policy

If you believe that this document breaches copyright please contact us providing details, and we will remove access to the work immediately and investigate your claim. 


\section{This time it's personal: Reappraisal after acquired brain injury}

Leanne Rowlands ${ }^{12}$, Rudi Coetzer ${ }^{12}, \&$ Oliver H. Turnbull ${ }^{1}$

School of Psychology, Bangor University, Bangor, U.K. ${ }^{1}$

The North Wales Brain Injury Service, Betsi Cadwaladr University Health Board, Colwyn Bay, U.K. ${ }^{2}$

Corresponding Author: Leanne Rowlands

leanne.rowlands@bangor.ac.uk

https://orcid.org/0000-0003-1130-5072

Word Count: 7273

Keywords: emotion regulation, reappraisal, cognitive control, brain injury, neurorehabilitation, personal reappraisal 


\begin{abstract}
Reappraisal is a widely investigated emotion regulation strategy, often impaired in those with acquired brain injury (ABI). Little is known, however, about the tools to measure this capacity in patients, who may find traditional reappraisal tasks difficult. Fifty five participants with ABI, and thirty five healthy controls (HCs), completed reappraisal tasks with personal and impersonal emotion elicitation components, questionnaires measuring reappraisal (the ERQ-CA), and neuropsychological assessment. The main findings demonstrated that both groups produced more reappraisals, and rated their reappraisal ideas as more effective for personal stimuli. The ABI group were significantly faster to generate reappraisals for personal, compared to impersonal, stimuli. Yet, participants with ABI performed worse than HCs on the majority of reappraisal components, across both reappraisal tasks. Results of regression analyses revealed significant relationships between certain measures of cognitive control and certain reappraisal components, which varied for the personal and impersonal reappraisal task. Notably, while inhibition predicted aspects of reappraisal in both the ABI and HC group, working memory was only related to reappraisal in participants with ABI. The study suggests that personal context plays a key role in reappraisal, and proposes a model to better understand the role of cognitive control across the reappraisal process.
\end{abstract}


Acquired brain injury (ABI) is a major public health concern (Corrigan, Selassie, \& Oman, 2010; Tagliaferri, Compagnone, Korsic, Servadei, \& Kraus, 2006), with survivors experiencing complex psychological impairment that can, in many cases, contribute to significant disability (Andelic, Hammergren, Bautz-Holter, Sveen, et al., 2009; Bramlett \& Dietrich, 2015; Dijkers, 2004). Of these consequences, the emotional element is typically the greatest source of distress in patients and their relatives (Diaz, Schwarzbold, Thais, Hohl, et al., 2012; Ergh, Rapport, Coleman, \& Hanks, 2002). Developing an understanding of ways to manage emotions after ABI, however, is further complicated by a methodological difficulty in measuring various emotional processes.

\section{Emotion regulation after brain injury}

Despite the large body of research into various emotional sequelae following brain injury (Williams \& Evans, 2003; Hesdorffer, Rauch, \& Tamminga, 2009, for a review), studies which have focused on emotion regulation (ER) strategies have been comparatively sparse (Beer \& Lombardo, 2007; Salas, Gross, \& Turnbull, 2019). There is widespread agreement in the literature that there are a range of strategies that can be employed to influence the intensity of emotions, and the way in which they are experienced and expressed (Gross \& Thompson, 2007; Gross, 2013; 2015). The Process Model, which is the most influential model of ER in the literature of neurotypical participants, consists of several strategies: situation selection, situation modification, attentional deployment, cognitive change (reappraisal), and response modulation (Gross, 2013). This model has provided an effective framework for the investigation of 
regulatory processes in the psychiatric literature (Hu, Zhang, Wang, Mistry, et al., 2014, for a meta-analysis), and may be a promising framework to investigate ER difficulties after brain injury (Salas et al., 2019, for a review).

By far the most well-investigated method for modulating feelings is the cognitive change strategy of reappraisal (Goldin, McRae, Ramel, \& Gross, 2008; Ochsner, Silvers, \& Buhle, 2012). This involves re-interpreting an event, sometimes changing its meaning, to modify its emotional consequences (Gross \& Thompson, 2007; Gross, 2015). Though the majority of research has focused on the down-regulation of negative emotions, reappraisal can also be used for the up-regulation of positive emotions (Gross, 2015; McRae \& Gross, 2020; Silton, Kahrilas, Skymba, Smith, Bryant, \& Heller, 2020). In neurologically healthy individuals, reappraisal has been a strategy of particular interest to understand various elements of emotional symptomatology, such as stress (Lewis, Yoon, \& Joormann, 2018), depression (Joormann \& Gotlib, 2010), and anxiety (Goldin, Manber-Ball, Werner, Heimberg, \& Gross, 2009).

The number of studies which have investigated reappraisal in people with ABI remains modest (Salas et al., 2019, for a review). However, the study of participants with brain injury has contributed much to the understanding of the underlying cognitive mechanisms of reappraisal. For example, Falquez, Couto, Ibañez, and colleagues (2014) found that lesions to the right superior frontal gyrus, an area responsible for inhibitory control, were associated with poorer reappraisal effectiveness. Additionally, investigations of the generative components of reappraisal have identified inhibition, verbal ability (Salas, Turnbull, \& Gross, 2014; Salas, Gross, Rafal, Viñas-Guasch, \& Turnbull, 2013), and working memory (Rowlands, Coetzer, \& Turnbull, 2019) as key components of the process. These generative components of reappraisal involve the timely construction of positive re-interpretations, and thus the creation of a 
reappraisal itself (i.e. creating a reappraisal). This generative aspect needs to be distinguished from other components, such as reappraisal effectiveness, since generating a reappraisal does not automatically mean it will be effective in altering one's emotional response.

The capacity to generate reappraisals can be selectively impaired in those with ABI. In particular, patients with brain injury took longer to generate a reappraisal (referred to as reappraisal difficulty), but when time was not considered they were able to produce a similar number of reappraisals (referred to as reappraisal productivity) to neurologically healthy controls (Salas et al., 2014). Extending on these findings, Rowlands et al (2019) found that patients with ABI were impaired across both reappraisal productivity and difficulty on an autobiographical recall reappraisal task, and reported less effective use of reappraisal to up-regulate positive emotions.

Considered together, these studies provide evidence, complementary to extensive neuroimaging work in healthy controls, suggesting that reappraisal is associated with areas of cognitive control (Buhle, Silvers, Wager, Lopez, et al., 2014, for meta-analysis), in particular working memory (Hendricks \& Buchanan, 2016). This two-stage process proposes that certain cognitive control capacities may be important for the early phase of disengaging from the initial appraisal (inhibition) and generating new interpretations (verbal ability) (Kalisch, 2009; Salas et al., 2014). In the second phase, the reappraisal needs to be maintained (using working memory), to shield it from the initial meaning (Kalisch, 2009). Recent evidence suggests that working memory may also play a role in the early phase, perhaps to keep the goal of reappraising in mind (Rowlands et al., 2019).

Some inconsistencies are, however, notable in previous studies. It is possible that these are due in part to the methods used to measure reappraisal (Ochsner \& Gross, 2005). For 
example, using a reappraisal task based on personal stimuli, Rowlands and colleagues (2019)

reported that working memory was the only significant predictor of reappraisal. In contrast, Salas and colleagues (2014), who used impersonal stimuli, reported that inhibition and verbal ability was predictive of reappraisal, but not working memory. To better understand the neuropsychological capacities involved in reappraisal, it is important to investigate these mechanisms for both types of stimuli, within the same sample.

\section{Emotion elicitation methods}

Researchers looking at various affective processes have increasingly studied emotion and its elicitation with more naturalistic methods (Chirico, Cipresso, \& Gaggioli, 2018; Salas, Radovic, \& Turnbull, 2012; Salas, Radovic, Castro, \& Turnbull, 2015; Siedlecka \& Denson, 2019). For example, participants being required to carry out a frustrating task with punishment to induce anger (Lobbestael, Arntz, \& Wiers, 2008), and mental imagery to induce a range of emotions (Zhang, Yu, \& Barrett, 2014). Of particular relevance for emotion elicitation may be personally salient information, as in Affective Story Recall (Turnbull, Evans, \& Owen, 2005). This involves generating personal affective memories, in order to reactivate and re-experience previous emotions (Prkachin, Williams-Avery, Zwaal, \& Mills, 1999). Autobiographical recall tasks have been shown to elicit target emotions effectively, including the associated subjective experience and peripheral physiology (Siedlecka \& Denson, 2019, for a review). Nonetheless, impersonal visual stimuli remain some of the most widely used emotional tools in experimental research (Lench, Flores, \& Bench, 2011).

The relevance of personal salience for emotion elicitation has prompted some to investigate the feasibility of such procedures for reappraisal research (Holland \& Kensinger, 2013; Speed, Levinson, Gross, Kiosses, \& Hajcak, 2017). Reappraisal tasks using 
autobiographical recall elicitation have largely shown that they are effective tools to measure the modulation of emotions, and show similar activation patterns in neuroimaging studies to traditional impersonal tasks (Holland \& Kensinger, 2013). These studies are, however, limited in that no comparisons have yet been made between such tasks, making it difficult to infer the difference between reappraisal for impersonal and personal affective stimuli.

The choice of elicitation procedures is a particularly important methodological question to consider in the context of participants with brain injury. This is because they often present with cognitive difficulties, which may impact upon their ability to effectively engage with visual stimuli (Levenson, 2007), or to follow the plot in film clips (Levenson, Ascher, Goodkind, McCarthy, et al., 2008, Salas et al., 2015). In addition, difficulties with empathy (de Sousa, McDonals, Rushby, Dimoska, \& James, 2010; Williams \& Wood, 2010) and emotion perception have long been established as common impairments following ABI (Bornhofen \& McDonald, 2008 for a review; Prigatano \& Pribram, 1982).

Only one study has systematically compared personal (i.e. internal) and impersonal (i.e. external) emotion elicitation tools in patients with neurological damage, and concluded that target emotions were elicited at higher intensities when recalling personal affective memories (Salas et al., 2015). Interestingly, such methodological comparisons have not been carried out to the same extent in emotion regulation research. Personal and impersonal reappraisal tasks have important methodological distinctions in the emotion elicitation component, which is a necessary first step to investigate the subsequent emotion regulation attempts. Where impersonal tasks involve the generation of emotional responses from stimuli presented from the outside (i.e. externally), and personal tasks involve the generation of emotion from stimuli which the person generates themselves (i.e. internally). 


\section{The present study}

Previous work has demonstrated that a personal emotion elicitation task (the Affective Story Recall task) can be used to measure reappraisal in neurological patients (Rowlands et al., 2019). However, with the absence of a direct comparison with an impersonal elicitation task (such as visual stimuli) there is a lack of understanding regarding the difference in reappraisal for personal and impersonal stimuli. The primary aim of the present study was to provide a direct comparison of performance on a reappraisal task with personally-salient stimuli (i.e. the ASRR task; Turnbull, Evans, \& Owen, 2005; Salas et al., 2015; Rowlands et al., 2019), with performance on a reappraisal task with standardised, impersonal, stimuli (i.e. pictures from the International Affective Picture System, IAPS; Lang, Bradley, \& Cuthbert, 2008) in both patients with $\mathrm{ABI}$ and healthy controls (Analysed under the sub-heading 'Personal versus impersonal reappraisal'). This aimed to provide better understanding of the importance of personal context for reappraisal, and which task might be easier or most effective for measuring reappraisal in patients with $\mathrm{ABI}$.

As part of a wider research study, there were a number of secondary aims. Firstly, to extend previous findings of reappraisal impairment (Rowlands et al., 2019; Salas et al., 2014), by investigating performance across both personal and impersonal reappraisal tasks, and with a larger sample (Analysed under the sub-heading 'How ABI affects reappraisal'). A further extension of previous work (Rowlands et al., 2019) was the investigation of the cognitive mechanisms underlying reappraisal, this time across two tasks (Analysed under the sub-heading 'Cognitive mechanisms of reappraisal'). Finally, the study aimed to investigate whether performance on both tasks correlated with an established reappraisal questionnaire (Gullone \& Taffe, 2012). This was to provide a measure of the validity of both personal and impersonal 
stimuli within a reappraisal task (Analysed under the sub-heading 'Reappraisal tasks and selfreport').

\section{Methods}

\section{Participants}

Fifty five participants with $\mathrm{ABI}$ and 35 healthy control participants were included in the study $(N=90)^{1}$. There were no significant differences in age or education between groups (see Table 1). Those with brain injury were prospectively recruited from a community outpatient rehabilitation service, the North Wales Brain Injury Service (NWBIS), Betsi Cadwaladr University Health Board $(n=39)$, and a small proportion recruited though Headway branches in North Wales $(n=12)$, and a rehabilitation day service, the Headforward Centre $(n=4)$. Inclusion criteria included the presence of a confirmed ABI (as per NWBIS criteria, Coetzer, Vaughan, Roberts, \& Rafal, 2003), a minimum of nine months since time of injury, and language abilities persevered to a level sufficient enough to complete the tasks (as judged by service staff). Exclusion criteria included being unable to give informed consent, the presence of a psychiatric disorder in need of acute care, a neurodegenerative or neurodevelopmental disorder. Healthy control participants were recruited from the North Wales community. For sample characteristics see Table 1.

\section{[Table 1 Here]}

\section{Measures}

Impersonal reappraisal task

This task was adapted from previous studies of reappraisal (Lench, et al., 2011, for a review; Lieberman, Inagaki, Tabibnia, \& Crockett, 2011; McRae et al., 2012; Salas et al., 2014).

\footnotetext{
${ }^{1} 51$ of these participants (57\%) were included in Rowlands et al (2019), however this previous study investigated reappraisal in $\mathrm{ABI}$ across discrete emotions, and thus included different, non-overlapping research questions.
} 
Tasks were carried out on a 13 inch laptop, providing step by step written instructions, to avoid memory bias. The task began with instructions, and two practice trials. Participants were then shown eight images from the IAPS, one at a time. Participants were required to verbally indicate the intensity of their emotional response to each image, on a zero to 10 scale. Following a written cue ('Think aloud about the positive sides. Try to be quick'), participants were required to verbally generate as many reappraisals as possible, as quickly as possible, before indicating emotional intensity again. See Figure 1 for visual representation of one trial.

\section{[ Figure 1 Here ]}

The images depicted a range of negative situations such as accidents, illness, and pollution, and evoked similar levels of valence and arousal. The mean of all sets of images indicated negative valence $(M=2.90, S D=0.72)$, and moderate arousal $(M=5.33, S D=0.52)$, as reported in the IAPS database (where valence is reported on a $1-9$ scale from extreme negative to extreme positive, and where arousal is reported on a $1-9$ scale from low to high). See Appendix A for task instruction.

\section{Personal reappraisal task}

For the personal reappraisal task (Affective Story Recall Reappraisal, ASRR; Rowlands et al., 2019) participants were presented with emotion words one at a time (i.e. 'sad', 'scared', 'angry', 'neutral', 'sad', 'scared', 'angry', 'neutral'), and were required to describe a personal event from memory which evoked a congruent emotion for each emotion word. Participants then indicated emotional intensity on a zero to 10 scale, before generating as many positive sides as they could, as quickly as they could. Following this, they rated emotional intensity again. The negative emotions ('sad', 'scared', and 'angry') involved the down-regulation of emotional intensity via reappraisal. The 'neutral' condition involved the up-regulation of low-intensity 
neutral events into higher-intensity positive ratings. All emotion words appeared twice, resulting in eight trials, and the participant was required to recall a different event for each emotion word. See Figure 2 for visual representation of one trial. Task instructions are presented in Appendix A (supplementary material).

\section{[ Figure 2 Here ]}

Given the wide range of cognitive abilities within the ABI population, a standardised exposure time was inappropriate. Participants, therefore, described their stories (personal task) and looked at the IAPS pictures (impersonal task) for as long as they felt necessary, but not exceeding three minutes. To avoid bias, participants were not instructed on the content of recalled stories, only that their story must evoke the instructed emotion for that trial. Both sets of stimuli were, therefore, not fully matched. However, the images in the impersonal task evoked a range of emotions, and for the personal task the scores across all discrete emotion trials were averaged, thus giving a 'composite' score for a range of emotions. Notably, both tasks present a trade-off, where impersonal IAPS stimuli allow for high experimenter control at the cost of ecological validity, and the personal task presents higher salience and ecological validity at the cost of loss of experimenter control. The validity of both reappraisal tasks was investigated in the present study (see results sub-heading 'Reappraisal tasks and self-report').

\section{Emotion regulation questionnaire}

The Emotion Regulation Questionnaire (adapted for children and adolescents) (ERQ-CA) (Gullone \& Taffe, 2012) measures self-reported use of reappraisal in daily life and is based upon the original and well-established Emotion Regulation Questionnaire (Gross \& John, 2003). The adapted version was chosen because of the simplified language. The ERQ-CA includes 6 items 
measuring reappraisal, scored on a 7-point Likert scale. The ERQ-CA has sound internal consistency $(\alpha=.86)$ and validity.

Cognitive control tasks

Working Memory was assessed using the Digit Span sub-task from the Wechsler Adult Intelligence Scale (WAIS IV) (Wechsler, 2008), an informative measure of this ability in individuals with ABI (Millis, Rosenthal, Novack, Sherer, et al., 2001). The full Digit Span subtask was used. This is because all dimensions of the sub-task are required to validly compute Scaled Scores for different age groups, and this was deemed necessary due to the wide range of participant age in the present sample (22 - 69 years). In addition, evidence suggests that the separate dimensions of Digit Span should be interpreted together (Bowden, Petrauskas, Bardenhagen, Meade, \& Simpson, 2013; Twamley, Palmer, Jeste, Taylor, \& Heaton, 2006).

Inhibition was measured with the Hayling sentence completion task from the Hayling and Brixton tests (Burgess \& Shallice, 1997), which reports sensitivity (Burgess \& Shallice, 1997), and validity in a sample of people with ABI (Odhuba, van den Broek, \& Johns, 2005). The overall Hayling score was used as a proxy of inhibition, as it includes the 'error score' and 'time taken to respond'. It is reported to have higher ecological validity, and correlates more highly with the inhibition factor on the Dysexecutive questionnaire (Odhuba, Van Den Broek, \& Johns, 2005).

Verbal Ability was measured using the Letter Fluency sub-task from the Delis-Kaplan Executive Function system (D-KEFS) (Delis, Kaplan, \& Kramer, 2001). This capacity has been shown to be one of the strongest predictors of cognitive control (Henry \& Crawford, 2004).

\section{Procedure}


Ethical approval was granted by the Health Board and Bangor University. Participants were invited to take part, and assessments carried out at Bangor University, NWBIS, Headforward Centre, or participants' homes. Following written informed consent, cognitive control tasks, reappraisal tasks, and the questionnaire were administered in random order, and completed in one session, with a short break half-way through. For the impersonal task, participants were randomly allocated to one set of eight images from the IAPS (Lang et al., 2008), out of a possible five sets that were had similar average valence and arousal (See Appendix B). Participants were told that the aim of both reappraisal tasks was to produce as many positive sides (reappraisals) as possible, as quickly as possible. Both tasks were recorded and transcribed verbatim, and provided three measurements: reappraisal productivity (the total number of reappraisals produced), reappraisal difficulty (the average time taken to produce a first reappraisal), and reappraisal effectiveness (the average difference in emotional intensity ratings before, and after, reappraising). All measures were completed by the first author (LR) or trained research assistants.

\section{Data Reduction}

Three components of reappraisal were considered for each of the study aims: 1) Reappraisal productivity involved the total sum of reappraisals produced across each task;2) Reappraisal difficulty was calculated by averaging the time taken to produce a first reappraisal across all the trials in each task, and 3) Reappraisal effectiveness consisted of the difference in score between the emotional intensity rated for each story recall (personal task) or IAPS picture (impersonal task) before and after reappraising, averaged across all trials.

The initial emotional intensity rating to the stimuli was identified as a covariate, and included in all analyses. It was calculated by averaging the initial emotional intensity rating 
across all trials. The personal reappraisal task included a neutral-to-positive condition. The emotional intensity for those trials (in the personal task alone) were reverse scored, before being averaged with the other negative trials (i.e. so that a baseline intensity of 0 becomes 10 ). Finally, scaled scores were computed for the cognitive control tasks.

\section{Data Analysis}

All analyses were carried out using the statistical software ' $R$ ' (R Core Team, 2019) with additional packages 'Robustbase', 'Complmrob', and 'Stats'. The alpha level was not adjusted

for multiple comparisons, because of the number of questions addressed and concern over loss of power (Cabin \& Mitchell, 2000).

Personal versus impersonal reappraisal

In order to answer the primary research question, reappraisal productivity, difficulty, and effectiveness were compared for the personal and impersonal reappraisal tasks using a series of analysis of covariance (ANCOVA), with average initial emotional intensity ratings to stimuli as a covariate, thus correcting for variations in baseline intensity. This was done for both groups separately.

How ABI affects reappraisal

To compare reappraisal components between the $\mathrm{HC}$ and $\mathrm{ABI}$ group, a series of ANCOVA analyses were carried out. This was done for both the personal and impersonal tasks separately, again with initial emotional intensity ratings as a covariate.

Cognitive control mechanisms of reappraisal

A series of forced entry robust multiple linear regression models were carried out, with 'MM' method (Salibián-Barrera, Aelst, \& Willems, 2008), and bootstrapped coefficients from 999 bootstrapped samples (as a form of model validation) (Babyak, 2004; Efron, 2003). A robust 
regression approach was used because of the violation of the assumption of normally-distributed residuals in the present data, which would have brought into question the validity of the coefficients from a non-robust multiple linear regression. Separate regression models were carried out for each outcome variable (reappraisal productivity, difficulty, and effectiveness) for the personal and impersonal reappraisal tasks. The predictor variables for each model consisted of the scaled scores for working memory (Digits, WAIS), inhibition (Hayling task), and verbal ability (D-KEFS). The average initial emotional intensity ratings were, again, controlled for by including these in the models as a covariate. This was done for each group separately, to gain insight into the potential relationships between neuropsychological mechanisms and reappraisal for each group.

\section{Reappraisal tasks and self-report}

As a final secondary aim, to investigate the validity and reliability of both reappraisal tasks, participant performance (i.e. reappraisal productivity, difficulty, and effectiveness for the personal and the impersonal task) was correlated with an established reappraisal questionnaire (ERQ-CA; Gullone \& Taffe, 2012), using partial Pearson correlation analyses, correcting for initial emotional intensity ratings on the tasks. Analyses were carried out for both groups separately.

\section{Results}

As could be expected, the ABI and HC group differed in their level of cognitive functioning and self-report use of reappraisal in daily life. The ABI group performed worse across most components of reappraisal on both tasks. See Table 2 below for descriptive statistics.

\section{[ Table 2 Here ]}




\section{Personal versus impersonal reappraisal}

Performance on the personal and impersonal reappraisal tasks were compared using ANCOVA for both the ABI and healthy control group separately, as this was deemed the most suitable analysis when controlling for the covariate.

\section{Acquired brain injury group}

Participants with ABI produced more reappraisals (reappraisal productivity) on the personal task, and this was marginally significant, $F(1,107)=2.03, p=.047, r=.19$, with a small effect size (see Figure 3). The ABI group took significantly less time to generate a first reappraisal (reappraisal difficulty) on the personal task, compared to the impersonal reappraisal task, $(F(1,107)=9.24, p=.001, r=.29)$, with a medium effect size (see Figure 4). This group also reported significantly more effective reappraisals (reappraisal effectiveness) for the personal $\operatorname{task}(F(1,107)=31.94, p<.001, r=.50)$, with a large effect size (see Figure 5).

\section{[Figure 3, 4 and 5 Here]}

Healthy control group

The healthy control group produced significantly more reappraisals (reappraisal productivity) on the personal task, compared to the impersonal task, $(F(1,67)=5.40, p=.025, r$ $=.27$ ), with a small-to-medium effect size (see Figure 3 ). The time taken to produce a first reappraisal (reappraisal difficulty) was similar for both tasks $(F(1,67)=1.64, p=.204, r=.15)$ (see Figure 4). The HC group also reported significantly more effective reappraisals (reappraisal effectiveness) for the personal task $(F(1,67)=6.90, p=.011, r=.31)$, with a medium effect size (see Figure 5). 
In summary, both groups reported more effective reappraisals (reappraisal effectiveness) on the personal task, compared to the impersonal stimuli2 (ABI group: $p<.001$; HC Group: $p=$ .011). Participants from both groups produced a greater number of reappraisals (reappraisal productivity) on the personal task (ABI group: $p=.047$; HC Group: $p=.025$ ). Participants with $\mathrm{ABI}$ also took significantly less time to produce a reappraisal (reappraisal difficulty) on the personal task $(p=.001)$, a feature unique to this group.

\section{How ABI affects reappraisal}

\section{Impersonal reappraisal task}

The results of the ANCOVA demonstrated that, on the impersonal reappraisal task, the ABI group took significantly longer to generate a first reappraisal (reappraisal productivity) compared to the healthy control group $(F(1,86)=37.00, p<.001, r=.54)$, with a large effect size (see Figure 4). Additionally, patients with ABI reported their reappraisals as significantly less effective (reappraisal effectiveness) on the impersonal reappraisal task compared to the healthy control group $(F(1,86)=11.97, p<.001, r=.34$, with a medium effect size) (see Figure 5), and produced significantly fewer reappraisals (reappraisal difficulty) $(F(1,86)=4.76, p=$ $.032, r=.23$, with a small effect size) (see Figure 3).

\section{Personal Reappraisal task}

On the personal reappraisal task, the ABI group took significantly longer to generate a first reappraisal (reappraisal difficulty) $(F(1,86)=29.72, p<.001, r=.51$, with a large effect size) (see Figure 4), and produced significantly fewer reappraisals (reappraisal productivity), compared to the healthy control group $(F(1,86)=5.49, p=.021, r=.24$, with a small effect

\footnotetext{
${ }^{2}$ A series of partial Pearson correlations were carried (with initial emotional intensity as a covariate) to investigate the relationships between reappraisal effectiveness, and productivity and difficulty. The only correlations of note were between reappraisal effectiveness and productivity on the personal task for the ABI group $(r=.47, p<.001)$, and the healthy control group $(r=.33, p=.055)$, suggesting that a greater number of reappraisals is associated with greater change in emotional intensity for stimuli with personal relevance.
} 
size) (see Figure 3). Both groups rated their reappraisals to be similar in terms of effectiveness (reappraisal effectiveness) $(F(1,86)=2.64, p=.110, r=.17$, with a small effect size) (see Figure 5).

\section{Cognitive mechanisms of reappraisal}

For results of all the regression analyses, see Table 3 and 4 (ABI group), and 5 and 6 (HC group). Only regression models with significant cognitive predictor variables are reported here. ABI Group

Reappraisal Productivity. The regression model marginally improved prediction of that number of reappraisals generated (reappraisal productivity) $\left(\mathrm{R}^{2}=.18, F(4,54)=9.21, p=.056\right)$ for the impersonal reappraisal task alone, and explained $18 \%$ of the variance. Within this model working memory was the single significant cognitive predictor variable $(\beta=0.52, p=.034)$. Reappraisal Difficulty. The regression model for the personal task, did not significantly improve prediction of the time taken to generate a reappraisal (reappraisal difficulty) $\left(\mathrm{R}^{2}=.13, F(4,54)=\right.$ $6.47, p=.166$ ), however working memory was a single significant cognitive predictor within the model $(\beta=-0.25, p=.041)$. The regression model on the impersonal task, did not significantly improve prediction of the time taken to generate a reappraisal (reappraisal difficulty) $\left(\mathrm{R}^{2}=.16\right.$, $F(4,54)=7.74, p=.102)$, however inhibition was a single significant cognitive predictor $(\beta=$ $0.56, p=.020)$

Reappraisal Effectiveness. For performance on the personal task in the ABI group, the model explained $22 \%$ of the variance, and significantly improved prediction of reappraisal effectiveness $\left(\mathrm{R}^{2}=.22, F(4,54)=14.35, p=.006\right)$. Inhibition scores were the only significant cognitive predictor variable within the model $(\beta=2.44, p=.037)$. On the impersonal task, inhibition was, again, a significant cognitive predictor of reappraisal effectiveness $(\beta=0.18, p=$ 
$.041)$. The overall model was, however, non-significant $\left(\mathrm{R}^{2}=.15, F(5,54)=8.51, p=.074\right)$, and explained $15 \%$ of the variance.

\section{[Table 3 and 4 here]}

\section{Healthy Control Group}

Reappraisal Difficulty. For performance on the impersonal reappraisal task in the HC group, the model explained $28 \%$ of the variance, and significantly improved prediction of the time taken to generate a first reappraisal (reappraisal difficulty) $\left(\mathrm{R}^{2}=.28, F(4,34)=11.69, p=\right.$ .019). Inhibition scores were the only significant cognitive predictor variable within the model ( $\beta$ $=-0.74, p=.004)$.

\section{[ Table 5 and 6 ]}

To summarise, for those with brain injury, better working memory appears to predict a greater number of reappraisals (reappraisal productivity) generated on the impersonal task, and less time to generate a reappraisal (reappraisal difficulty) on the personal task ${ }^{3}$. Better inhibition appears to be an important capacity for the rated effectiveness of reappraisals (reappraisal effectiveness) on both tasks, and less time to generate a reappraisal (reappraisal difficulty) on the impersonal task alone. For the healthy control group, inhibition predicted less time to generate a reappraisal (reappraisal difficulty) on the personal reappraisal task. As can be seen in Tables 3 6, the covariate baseline emotional intensity was predictive of reappraisal effectiveness. This might be expected because reappraisal effectiveness is calculated from the baseline emotional intensity and the intensity after reappraising. Baseline emotional intensity was also positive predictive of reappraisal productivity on the impersonal task for the ABI group.

\footnotetext{
${ }^{3}$ We acknowledge that the Digits Backwards dimension of the Digit Span (WAIS IV) is a true proxy of working memory. However, as previously mentioned, scaled scores (which correct for age effects) cannot be calculated from this dimension alone. Nonetheless, it is important to acknowledge that with a re-analysis with the Digits Backwards dimension as a cognitive predictor variable, these effects were lost (Impersonal task: reappraisal productivity $(\beta=0.28, p=141)$; Personal task: reappraisal difficulty $(\beta=-0.18, p=.166)$
} 


\section{Reappraisal tasks and self-report}

A series of partial Pearson correlations analyses were carried out, to investigate the relationships between performance on both tasks, with self-report use of reappraisal on the ERQCA. For full correlation results, see Table 7. Only significant relationships are reported here.

\section{[ Table 7 Here ]}

ABI Group

Self-report use of reappraisal on the ERQ-CA showed a significant moderate positive correlation with reported reappraisal effectiveness $(r=.56, p<.001)$, a significant moderate positive correlation with the total number of reappraisals produced (reappraisal productivity) $(r=$ $.41, p=.002$ ), and a significant moderate negative correlation with the time taken to generate a first reappraisal (reappraisal difficulty) $(r=-.34, p=.011)$, on the personal reappraisal task. On the impersonal reappraisal task, ERQ-CA scores demonstrated a significant moderate positive correlation with the total number of reappraisals produced (reappraisal productivity) $(r=.30, p=$ $.026)$.

\section{Healthy Control Group}

For the HC group, the general picture is much less informative. Participants' self-report use of reappraisal on the ERQ-CA showed a significant moderate positive correlation with the total number of reappraisals produced (reappraisal productivity) on the impersonal task alone ( $r$ $=.40, p=.018)$. The ERQ-CA was not notably related to any other component of reappraisal across either task.

\section{Discussion}

The present study aimed, particularly, to gain further insight into how reappraisal performance may vary depending on the personal relevance of task stimuli. Secondary aims were 
to extend previous findings regarding reappraisal impairment in people with $\mathrm{ABI}$, the underlying cognitive mechanisms of this ER strategy, and finally, to investigate correlations between task performance and self-report use of reappraisal, as a measure of task validity.

\section{Personal versus impersonal reappraisal}

An important conclusion of the present study is that both groups of participants generated more reappraisals, and more effective reappraisals, to their own recalled memories. That is, generating new meanings, and successfully changing emotional intensity, appeared to be less difficult when reappraising their own recalled events, in particular for the ABI group. These findings suggest that a reappraisal task with personally salient emotional memories as the elicitation component (as in previous studies in neurotypical individuals, Holland \& Kensinger, 2013; Speed et al., 2017) can be a highly successful tool to measure ER. A limitation of the previous literature, however, was the absence of a direct comparison with a standardised, impersonal, external elicitation measure. The findings of the present study suggest that personal salience may facilitate the reappraisal process.

A key theme of the finding is the potential importance of context (Aldao, 2013). The high ecological validity of the personal reappraisal task likely reflects how reappraisal plays out in more real-life contexts. That is, reappraising emotions based on real, and sometimes powerful, events is a complex and dynamic process (Kalisch, 2009). Better generation and more effective reappraisal for such events might mirror how regulatory strategies unfold in response to higher and more complex situational demands (c.f. the regulatory flexibility literature; Bonanno \& Burton, 2013; Burton \& Bonanno, 2016).

In particular, reappraisal is thought to be more effective in situations that are uncontrollable, where the person can only regulate the self(Troy, Shallcross, \& Mauss, 2013). 
These were the types of events frequently recalled on the personal task (common themes include illness, death, relationships). Such judgements require adequate situational information (context), which is minimal in impersonal stimuli, such as IAPS pictures. Ambiguity and a lack of information seems likely to decrease situational demands, and leaves individuals with little sense of agency to regulate the self.

Given the absence of adequate information on the impersonal task, participants might be required to think hypothetically about how abstract ideas can change the emotional outcome of the picture's content (Salas et al., 2013). Such a skill surely requires abstract reasoning, and verbal ability, both impairments which have been shown to compromise reappraisal generation (for a detailed description see Salas et al., 2013). If the impersonal reappraisal task relies more heavily on more abstract aspects of cognition, it is possible that differences in cognitive ability contribute to the lower effectiveness of reappraisals, and would explain why the ABI group alone took longer to generate a reappraisal on the impersonal task. This may be particularly marked in dysexecutive patients, who often struggle with disengagement from immediate experience and manipulating thoughts (Gomez Beldarrain, Garcia-Monco, Astigarraga, et al., 2005; Salas et al., 2012). Such inflexibility, and lack of a reflective stance, may be more pronounced when emotions have been generated externally. However, when emotions are self-generated through memory recall, dysexecutive patients may be less influenced by perceptual aspects of stimuli and therefore able to utilise the personal content and relevance to manipulate ideas. Appendix C demonstrates examples of reappraisals across both tasks, which reflect these possible explanations.

\section{How ABI affects reappraisal}


If reappraisal is a two-stage process (Kalisch, 2009), the present study suggests that having a brain injury especially compromises the early, generative, stage, regardless of the type of stimulus that is reappraised. This provides further support to previous findings, which demonstrated that a brain injury can compromise the capacity to generate reappraisals, and to do so quickly (Rowlands et al., 2019).

For the ABI group, reappraisal effectiveness seemed to be influenced by the nature of the reappraisal task. That is, when reappraising impersonal stimuli, the ABI group reported significantly poorer reappraisal effectiveness compared to healthy controls, but this difference was not present for the personal task. The observation that reappraisal effectiveness was similar to healthy controls on the personal task, is consistent with previous findings that patients with brain injury were able to down-regulate negative emotions at similar levels to a healthy control group (Rowlands et al., 2019). A likely explanation for the difference on the impersonal task is that those with impaired cognitive control may experience more difficulties for impersonal or abstract situations.

\section{The neglected role of context}

This study shows that there is an important distinction between reappraisal for personal and impersonal material, especially for the ABI group. It appears that when reappraising material that is relevant to the self, spontaneous generation of information (or idea generation) is easier. Participants are, therefore, able to use this contextual information to build more effective reinterpretations, and more quickly. Impersonal (i.e. external) stimuli may present an additional challenge, because there is insufficient contextual information to build reappraisals.

The notion that contextual information is important is consistent with a developing line of research, which suggests that context effects are central in ER (Aldao, 2013, for a review; 
Bonanno \& Burton, 2013). For example, in contexts where stressful situations can be controlled, the use of reappraisal is considered maladaptive (Troy, Shallcross \& Mauss, 2013). Additionally, the adaptiveness of a reappraisal might rely on the realism of the information used to build the new meanings (Aldao, 2013; Gross 1998; van't Wout, Chang, \& Sanfey, 2010). It is, therefore, possible that contextual information is critical to building positive reinterpretations, that are then accepted as realistic.

This idea can be seen anecdotally in the example below, of a participant in the ABI group.

Impersonal task (Sad Girls picture): "We don't know what's happened to them. In my mind, the three of them are crying like something big has happened. We don't know, maybe someone has been hurt. I look on the dark side, but when I try not to look on the dark side, maybe it's not a terrible thing but a friend has gone to work in another country and they are just missing the friend. We just don't know. Because I don't know I think it is like the dark side, so [how I feel] doesn't change".

Personal task (Scared when joined a community brain injury group): "Positive side is that now I enjoy going. And if I get invited to other places now, I will go. I enjoy taking part in all the activities, and meeting new people. It's comforting to meet people who have gone through the same as you, and they know what you've been through and can help. It's nice to be with people that listen to you there too, like the volunteers and that".

In the impersonal task, the participant attempted to seek out contextual information to build reappraisals, but then rejects them because they were apparently not credible. In contrast, when faced with a personal story, where there is an abundance of information to build reappraisals, they were more easily able to accept the new meaning as credible. It seems, 
therefore, that being able to generate a reappraisal is not always enough, participants have to then accept the reappraisal in order for it to successfully alter emotional responses. Given the absence of contextual information in impersonal stimuli, reappraisals may be harder to accept, and thus do not change the intensity of emotions to the same extent.

\section{Cognitive mechanisms of reappraisal}

The present study found associations between several cognitive control capacities and components of reappraisal. While it appears that cognitive capacities are important for reappraisal, their link to specific reappraisal components seems to depend on both the nature of the stimuli and the participant group. The most notable finding was that, for those with ABI, inhibition appeared to be particularly important for a reappraisal's effectiveness at changing emotional intensity, regardless of stimuli. This is comparable to previous studies in neurologically heathy participants (Buhle et al., 2014, for meta-analysis). Inhibition was also predictive of the time taken to generate a reappraisal on the impersonal task (for the ABI group) and the personal task (HC group). This is a similar finding to a previous study of reappraisal in ABI (Salas et al., 2014), and suggests that being able to effectively inhibit the initial appraisal is a necessary step to generate an alternative interpretation quickly.

Working memory appeared to be important for some elements of reappraisal for the ABI group alone. Specifically, better working memory appeared to support quicker generation of reappraisals for the personal task, and seemed important for generating a greater number of reappraisals on the impersonal task. This extends well-established findings of working memory and reappraisal (Hendricks \& Buchanan, 2016; Jasielska, Kaczmarek, Brońska, Dominiak et al., 2017; McRae et al., 2012; Rowlands et al., 2019). It is, somewhat, surprising that working 
memory was not found to be predictive of the number of reappraisals produced on the personal task, given the previous findings using that same task (Rowlands et al., 2019).

These findings are, indeed, very complex, but what is especially noteworthy is that cognitive control appears to be more predictive of reappraisal performance for the ABI group, and for the impersonal stimuli. This could be because such capacities might be required to a much greater extent for ambiguous situations (e.g. IAPS pictures), where there is not enough contextual information to draw from. Additionally, the highly varied nature of cognitive ability in the ABI group may have allowed the detection of these effects, whereas the majority of participants in the healthy control group scored within a restricted 'average' range for cognitive control.

\section{Reappraisal tasks and self-report}

The strong associations between task performance on the personal task, and the selfreport use of reappraisal on an established questionnaire (ERQ-CA), suggest that the personal task is especially reliable and appropriate for measuring this ER strategy in participants with brain injury, and has strong ecological validity. Such associations were not found for the healthy control group. This may be related to the narrower range of reappraisal performance in this group, or a discrepancy between habitual use of reappraisal in daily life, and what people are capable of doing when they are instructed in laboratory tasks (McRae et al., 2012; Troy,

Wilhelm, Shallcross, \& Mauss, 2010; Weber, Assunção, Martin, Westmeyer, \& Geisler, 2014). Such tasks focus exclusively on the 'implementation stage' of ER, and in daily life people would have to first choose reappraisal as the ER strategy to be implemented (i.e. the 'selection stage') (McRae \& Gross, 2020; Sheppes, Scheibe, Suri, Radu, et al., 2014). It is also possible that people may report frequent use of reappraisal in their lives, but do so rather unsuccessfully (Perchtold, 
Papousek, Fink, Weber, et al., 2019). The present study's findings provide support that the number of reappraisals generated on the impersonal task is somewhat associated with the validated questionnaire, regardless of group.

\section{A model of reappraisal: context and cognition}

These findings support the idea that reappraisal is a dynamic two-stage process, consisting of early and late phases (Kalisch, 2009; Paret, Brenninkmeyer, Yuen, Gartmann, et al., 2011). Expanding on the Implementation-Maintenance model (Kalisch, 2009), Salas and colleagues (2014) suggested that the early phase, reappraisal generation, requires inhibition as a first step (to disengage from the initial appraisal), and verbal ability as a process to facilitate the generation of new meanings. As discussed above, contextual information may facilitate the generative process further.

An adapted two-stage model of reappraisal is proposed here, considering results from the present study and previous findings (Kalisch, 2009; McRae et al., 2012; Ochsner, Silvers, \& Buhle, 2012; Paret et al., 2011; Rowlands et al., 2019; Salas et al., 2013; Salas et al., 2014). See Figure 6. In the first phase, reappraisal generation, inhibition is required to disengage from the initial appraisal (1). If successful, the initial meaning and goal of reappraising is kept in mind supported by working memory (2), and verbal ability and working memory are required to generate re-interpretations of the initial meaning (3).

If the first phase is successful, the second phase of reappraisal maintenance is entered. Here, working memory keeps track of the new appraisal (4), protecting it from the automatic appraisal. It is likely that monitoring is then important to track the reappraisal's success, and modify if necessary (5). This process seems mediated by the available contextual information, including the generation and maintenance components. In the absence of contextual information 
(e.g. impersonal stimuli), participants depend on cognitive control capacities to a higher degree, and draw upon reasoning skills to translate abstract ideas into reappraisals. The reappraisal's success then, in large part, relies on how well the automatic appraisal has been inhibited in the first phase.

\section{[ Figure 6 Here ]}

\section{Implications and Future Directions}

The present study's findings are important for neuropsychological rehabilitation in two ways. Firstly, by demonstrating that patients with ABI might be vulnerable to reappraisal impairment, in particular in ambiguous situations, or ones in which they must act quickly. This opens the possibility of facilitating the process by changing environmental demands (time) or providing support (contextual information). Secondly, it suggests that, for those with ABI, a cognitively effortful strategy may not be the best choice to modulate feelings. For example, there is evidence to suggest that strategies such as attentional deployment (Isaacowitz, Toner, \& Neupert, 2009; Sheppes, Brady, \& Samson, 2014) or situation selection (Webb, Lindquist, Jones, et al., 2018) might be more appropriate for those low in cognitive resources.

Despite this contribution, the present study has some limitations. One is related to the mixed, and highly varied, sample of participants with ABI. However, this is also positive in that it is reflective of the clinical population. Another issue is that the measure of reappraisal effectiveness was dependant on self-report changes in emotional intensity, and therefore may have been vulnerable to experimenter demands. It is important to note, however, that self-report is correlated with physiology during reappraisal (Troy et al., 2010). Finally, it is worthwhile to mention that the sample size was relatively small for the multiple regression analyses, in 
particular for the HC group. It is, therefore, possible that the coefficients are unstable, and may not generalise to other samples.

\section{Conclusion}

The findings of the present study enhance the understanding of which tools might be most appropriate to capture elements of reappraisal, and in particular for neurological populations. It is suggested that a personal task (such as the ASRR) may be technically superior to impersonal stimuli, and cognitively less effortful because it is facilitated by context. However, reappraisal remains a difficult strategy for patients, even when facilitated by personal context. Considered together, the use of a personally-salient task as an assessment tool is highly recommended, in particular for people with ABI. It can also be extended into the realm of intervention, and potentially used as a therapeutic tool, given its salience.

\section{Sample size calculation}

Given the specialised nature of the ABI sample, the size was determined by the highest possible number of recruited patients within the current restraints of the study.

\section{Acknowledgements}

This study was supported by EU Social Fund through the Welsh Government. We would like to thank all the participants for contributing to this work, and the research assistants involved in the study.

\section{References}

Aldao, A. (2013). The future of emotion regulation research: Capturing context. Perspectives on Psychological Science, 8(2), 155-172. DOI: https://doi.org/10.1177/1745691612459518

Andelic, N., Hammergren, N., Bautz-Holter, E., Sveen, U., Brunborg, C., \& Røe, C. (2009). Functional outcome and health-related quality of life 10 years after moderate-to-severe traumatic brain 
injury. Acta Neurologica Scandinavica, 120(1), 16-23. DOI: https://doi.org/10.1111/j.16000404.2008.01116.x

Babyak, M. A. (2004). What you see may not be what you get: a brief, nontechnical introduction to overfitting in regression-type models. Psychosomatic medicine, 66(3), 411-421.

Beer, J. S., \& Lombardo, M. V. (2007). Insights into emotion regulation from neuropsychology. In J. J., Gross (Ed.), Handbook of emotion regulation, (pp. 69-86), New York: The Guilford Press.

Bonanno, G. A., \& Burton, C. L. (2013). Regulatory flexibility: An individual differences perspective on coping and emotion regulation. Perspectives on Psychological Science, 8(6), 591-612. DOI: https://doi.org/10.1177/1745691613504116

Bornhofen, C., \& Mcdonald, S. (2008). Emotion perception deficits following traumatic brain injury: A review of the evidence and rationale for intervention. Journal of the International Neuropsychological Society, 14(4), 511-525. DOI: https://doi.org/10.1017/S1355617708080703

Bowden, S. C., Petrauskas, V. M., Bardenhagen, F. J., Meade, C. E., \& Simpson, L. C. (2013). Exploring the dimensionality of digit span. Assessment, 20(2), 188-198. DOI: https://doi.org/10.1177/1073191112457016

Bramlett, H. M., \& Dietrich, W. D. (2015). Long-term consequences of traumatic brain injury: current status of potential mechanisms of injury and neurological outcomes. Journal of neurotrauma, 32(23), 1834-1848. DOI: https://doi.org/10.1089/neu.2014.3352

Buhle, J. T., Silvers, J. A., Wager, T. D., Lopez, R., Onyemekwu, C., Kober, H., ... \& Ochsner, K. N. (2014). Cognitive reappraisal of emotion: a meta-analysis of human neuroimaging studies. Cerebral cortex, 24(11), 2981-2990. DOI: https://doi.org/10.1093/cercor/bht154

Burgess, P. W., \& Shallice, T. (1997). The Hayling and Brixton Tests. Thurston, Suffolk: Thames Valley Test Company.

Burton, C. L., \& Bonanno, G. A. (2016). Regulatory flexibility and its role in adaptation to aversive events throughout the lifespan. In A. D. Ong \& C. E. Löckenhoff (Eds.), Bronfenbrenner series on the ecology of human development. Emotion, aging, and health (pp. 71-94). Washington, DC, US: American Psychological Association. http://dx.doi.org/10.1037/14857-005

Cabin, R. J., \& Mitchell, R. J. (2000). To Bonferroni or not to Bonferroni: when and how are the questions. Bulletin of the Ecological Society of America, 81(3), 246-248.

Chirico, A., Cipresso, P., \& Gaggioli, A. (2018). Psychophysiological Specificity of Four Basic Emotions Through Autobiographical Recall and Videos. In International Symposium on 
Pervasive Computing Paradigms for Mental Health (pp. 1-8). Springer, Cham. DOI: https://doi.org/10.1007/978-3-030-01093-5_1

Coetzer, B. R., Vaughan, F. L., Roberts, C. B., \& Rafal, R. (2003). The development of a holistic, community based neurorehabilitation service in a rural area. Journal of Cognitive Rehabilitation, 21(1), 4-15.

Corrigan, J. D., Selassie, A. W., \& Orman, J. A. L. (2010). The epidemiology of traumatic brain injury. The Journal of head trauma rehabilitation, 25(2), 72-80. DOI: 10.1097/HTR.0b013e3181ccc8b4

De Sousa, A., McDonald, S., \& Rushby, J. (2012). Changes in emotional empathy, affective responsivity, and behavior following severe traumatic brain injury. Journal of Clinical and Experimental Neuropsychology, 34(6), 606-623. DOI: https://doi.org/10.1080/13803395.2012.667067

Delis, D. C., Kaplan, E., \& Kramer, J. H. (2001). Delis-Kaplan Executive function system: examiners manual. Psychological Corporation.

Diaz, A. P., Schwarzbold, M. L., Thais, M. E., Hohl, A., Bertotti, M. M., Schmoeller, R., ... \& Walz, R. (2012). Psychiatric disorders and health-related quality of life after severe traumatic brain injury: a prospective study. Journal of Neurotrauma, 29(6), 1029-1037.

Dijkers, M. P. (2004). Quality of life after traumatic brain injury: a review of research approaches and findings. Archives of physical medicine and rehabilitation, 85, 21-35. DOI: https://doi.org/10.1016/j.apmr.2003.08.119

Efron, B. (2003). Second thoughts on the bootstrap. Statistical Science, 18(2), 135-140. DOI: doi:10.1214/ss/1063994968

Ergh, T. C., Rapport, L. J., Coleman, R. D., \& Hanks, R. A. (2002). Predictors of caregiver and family functioning following traumatic brain injury: Social support moderates caregiver distress. The Journal of head trauma rehabilitation, 17(2), 155-174.

Falquez, R., Couto, B., Ibanez, A., Freitag, M. T., Berger, M., Arens, E. A., ... \& Barnow, S. (2014). Detaching from the negative by reappraisal: the role of right superior frontal gyrus (BA9/32). Frontiers in Behavioral Neuroscience, 8, 165. DOI: https://doi.org/10.3389/fnbeh.2014.00165 
Goldin, P. R., Manber-Ball, T., Werner, K., Heimberg, R., \& Gross, J. J. (2009). Neural mechanisms of cognitive reappraisal of negative self-beliefs in social anxiety disorder. Biological psychiatry, 66(12), 1091-1099. DOI: https://doi.org/10.1016/j.biopsych.2009.07.014

Goldin, P. R., McRae, K., Ramel, W., \& Gross, J. J. (2008). The neural bases of emotion regulation: reappraisal and suppression of negative emotion. Biological psychiatry, 63(6), 577-586. DOI: https://doi.org/10.1016/j.biopsych.2007.05.031

Gomez Beldarrain, M. G., Garcia-Monco, J. C., Astigarraga, E., Gonzalez, A., \& Grafman, J. (2005). Only spontaneous counterfactual thinking is impaired in patients with prefrontal cortex lesions. Cognitive Brain Research, 24(3), 723-726.

Gross, J. J. (1998). Antecedent- and response-focused emotion regulation: Divergent consequences for experience, expression, and physiology. Journal of Personality and Social Psychology, 74, 234237. DOI: $10.1037 / 0022-3514.85 .2 .348$

Gross, J. J. (2013). Emotion regulation: Conceptual and empirical foundations. In J. J. Gross (Ed.), Handbook of emotion regulation (pp.3-21). New York: Guilford Press.

Gross, J. J. (2015). Emotion regulation: Current status and future prospects. Psychological Inquiry, 26(1), 1-26. DOI: https://doi.org/10.1080/1047840X.2014.940781

Gross, J. J., \& John, O. P. (2003). Individual differences in two emotion regulation processes: implications for affect, relationships, and well-being. Journal of personality and social psychology, 85(2), 348. DOI: https://doi.org/10.1037/0022-3514.85.2.348

Gross, J. J., \& Thompson, R. A. (2007). Emotion regulation: Conceptual foundations. In J. J. Gross (Ed.), Handbook of emotion regulation (pp.3-24). New York: Guilford Press.

Gullone, E., \& Taffe, J. (2012). The Emotion Regulation Questionnaire for Children and Adolescents (ERQ-CA): A psychometric evaluation. Psychological assessment, 24(2), 409.

Hendricks, M. A., \& Buchanan, T. W. (2016). Individual differences in cognitive control processes and their relationship to emotion regulation. Cognition and Emotion, 30(5), 912-924. DOI https://doi.org/10.1080/02699931.2015.1032893

Henry, J. D., \& Crawford, J. R. (2004). A meta-analytic review of verbal fluency performance in patients with traumatic brain injury. Neuropsychology, 18(4), 621. DOI: http://dx.doi.org/10.1037/0894-4105.18.4.621 
Hesdorffer, D. C., Rauch, S. L., \& Tamminga, C. A. (2009). Long-term psychiatric outcomes following traumatic brain injury: a review of the literature. The Journal of head trauma rehabilitation, 24(6), 452-459. DOI: 10.1097/HTR.0b013e3181c133fd

Holland, A. C., \& Kensinger, E. A. (2013). The neural correlates of cognitive reappraisal during emotional autobiographical memory recall. Journal of Cognitive Neuroscience, 25(1), 87-108.

Hu, T., Zhang, D., Wang, J., Mistry, R., Ran, G., \& Wang, X. (2014). Relation between emotion regulation and mental health: a meta-analysis review. Psychological reports, 114(2), 341-362. DOI: https://doi.org/10.2466/03.20.PR0.114k22w4

Isaacowitz, D. M., Toner, K., \& Neupert, S. D. (2009). Use of gaze for real-time mood regulation: Effects of age and attentional functioning. Psychology and Aging, 24(4), 989-994. DOI: http://dx.doi.org/10.1037/a0017706

Jasielska, A., Kaczmarek, L., Brońska, A., Dominiak, M., Niemier, K., Patalas, D., ... \& Tomczak, M. (2017). The relationship between working memory and emotion regulation strategies. Roczniki Psychologiczne/Annals of Psychology, 18(4), 567-578.

Joormann, J., \& Gotlib, I. H. (2010). Emotion regulation in depression: relation to cognitive inhibition. Cognition and Emotion, 24(2), 281-298. DOI: https://doi.org/10.1080/02699930903407948

Kalisch, R. (2009). The functional neuroanatomy of reappraisal: time matters. Neuroscience \& Biobehavioral Reviews, 33(8), 1215-1226. DOI: https://doi.org/10.1016/j.neubiorev.2009.06.003 Lang, P. J., Bradley, M. M., \& Cuthbert, B. N. (1997). International affective picture system (IAPS): Technical manual and affective ratings. NIMH Center for the Study of Emotion and Attention, 1, $39-58$.

Lench, H. C., Flores, S. A., \& Bench, S. W. (2011). Discrete emotions predict changes in cognition, judgment, experience, behavior, and physiology: a meta-analysis of experimental emotion elicitations. Psychological bulletin, 137(5), 834.

Levenson, R. W. (2007). Emotion elicitation with neurological patient. In C. James and J. Allen (Eds.), The Handbook of Emotion Elicitation and Assessment, (pp. 158-168), Cambridge: University Press.

Levenson, R. W., Ascher, E. A., Goodkind, M. S., McCarthy, M. E., Sturm, V. E., \& Werner, K. H. (2008) Laboratory testing of emotion and frontal cortex. In G. Goldenberg and B. Miller 
(Eds.), Handbook of Clinical Neuropsychology and Behavioural Neurology, (pp. 489 - 498). New York: Elsevier.

Lewis, E. J., Yoon, K. L., \& Joormann, J. (2018). Emotion regulation and biological stress responding: associations with worry, rumination, and reappraisal. Cognition and Emotion, 32(7), 1487-1498. DOI: https://doi.org/10.1080/02699931.2017.1310088

Lieberman, M. D., Inagaki, T. K., Tabibnia, G., \& Crockett, M. J. (2011). Subjective responses to emotional stimuli during labeling, reappraisal, and distraction. Emotion, 11(3), 468. DOI: http://dx.doi.org/10.1037/a0023503

Lobbestael, J., Arntz, A., \& Wiers, R. W. (2008). How to push someone's buttons: A comparison of four anger-induction methods. Cognition \& Emotion, 22(2), 353-373. DOI: https://doi.org/10.1080/02699930701438285

McRae, K., \& Gross, J. J. (2020). Emotion regulation. Emotion, 20(1), 1-9. DOI: http://dx.doi.org/10.1037/emo0000703

Millis, S. R., Rosenthal, M., Novack, T. A., Sherer, M., Nick, T. G., Kreutzer, J. S., ... \& Ricker, J. H. (2001). Long-term neuropsychological outcome after traumatic brain injury. The Journal of head trauma rehabilitation, 16(4), 343-355.

Ochsner, K. N., \& Gross, J. J. (2005). The cognitive control of emotion. Trends in cognitive sciences, 9(5), 242-249. DOI: https://doi.org/10.1016/j.tics.2005.03.010

Ochsner, K. N., Silvers, J. A., \& Buhle, J. T. (2012). Functional imaging studies of emotion regulation: a synthetic review and evolving model of the cognitive control of emotion. Annals of the New York Academy of Sciences, 1251, E1. DOI: 10.1111/j.1749-6632.2012.06751.x

Odhuba, R. A., Van Den Broek, M. D., \& Johns, L. C. (2005). Ecological validity of measures of executive functioning. British Journal of Clinical Psychology, 44(2), 269-278. DOI: https://doi.org/10.1348/014466505X29431

Paret, C., Brenninkmeyer, J., Meyer, B., Yuen, K. S., Gartmann, N., Mechias, M. L., \& Kalisch, R. (2011). A test for the implementation-maintenance model of reappraisal. Frontiers in Psychology, 2, 216. DOI: https://doi.org/10.3389/fpsyg.2011.00216

Perchtold, C. M., Papousek, I., Fink, A., Weber, H., Rominger, C., \& Weiss, E. M. (2019). Gender differences in generating cognitive reappraisals for threatening situations: Reappraisal capacity shields against depressive symptoms in men, but not women. Frontiers in Psychology, 10, 553. DOI: https://doi.org/10.3389/fpsyg.2019.00553 
Prigatano, G. P., \& Pribram, K. H. (1982). Perception and memory of facial affect following brain injury. Perceptual and Motor Skills, 54(3), 859-869. DOI: https://doi.org/10.2466/pms.1982.54.3.859

Prkachin, K. M., Williams-Avery, R. M., Zwaal, C., \& Mills, D. E. (1999). Cardiovascular changes during induced emotion: An application of Lang's theory of emotional imagery. Journal of Psychosomatic Research, 47(3), 255-267. DOI: https://doi.org/10.1016/S0022-3999(99)00036-7

Rowlands, L., Coetzer, R., \& Turnbull, O. H. (2019). Good things better? Reappraisal and discrete emotions in acquired brain injury. Neuropsychological rehabilitation, 1-29. DOI: https://doi.org/10.1080/09602011.2019.1620788

Salas Riquelme, C. E., Turnbull, O. H., \& Gross, J. J. (2014). Reappraisal generation after acquired brain damage: The role of laterality and cognitive control. Frontiers in Psychology, 5, 242. DOI: https://doi.org/10.3389/fpsyg.2014.00242

Salas, C. E., Gross, J. J., \& Turnbull, O. H. (2019). Using the process model to understand emotion regulation changes after brain injury. Psychology \& Neuroscience, 12(4), 430. DOI: https://doi.org/10.1037/pne0000174

Salas, C. E., Gross, J. J., Rafal, R. D., Viñas-Guasch, N., \& Turnbull, O. H. (2013). Concrete behaviour and reappraisal deficits after a left frontal stroke: a case study. Neuropsychological rehabilitation, 23(4), 467-500. DOI: https://doi.org/10.1080/09602011.2013.784709

Salas, C. E., Radovic, D., \& Turnbull, O. H. (2012). Inside-out: Comparing internally generated and externally generated basic emotions. Emotion, 12(3), 568. DOI: http://dx.doi.org/10.1037/a0025811

Salas, C. E., Radovic, D., Castro, O., \& Turnbull, O. H. (2015). Internally and externally generated emotions in people with acquired brain injury: preservation of emotional experience after right hemisphere lesions. Frontiers in psychology, 6, 101.

Salibián-Barrera, M., Van Aelst, S., \& Willems, G. (2008). Fast and robust bootstrap. Statistical Methods and Applications, 17(1), 41-71. DOI: $\underline{\text { https://doi.org/10.1007/s10260-007-0048-6 }}$

Sheppes, G., Brady, W. J., \& Samson, A. C. (2014). In (visual) search for a new distraction: The efficiency of a novel attentional deployment versus semantic meaning regulation strategies. Frontiers in psychology, 5, 346. DOI: https://doi.org/10.3389/fpsyg.2014.00346 
Sheppes, G., Scheibe, S., Suri, G., Radu, P., Blechert, J., \& Gross, J. J. (2014). Emotion regulation choice: A conceptual framework and supporting evidence. Journal of Experimental Psychology: General, 143(1), 163. DOI: https://doi.org/10.1037/a0030831

Siedlecka, E., \& Denson, T. F. (2019). Experimental methods for inducing basic emotions: A Qualitative review. Emotion Review, 11(1), 87-97. DOI: https://doi.org/10.1177/1754073917749016

Silton, R. L., Kahrilas, I. J., Skymba, H. V., Smith, J., Bryant, F. B., \& Heller, W. (2020). Regulating positive emotions: Implications for promoting well-being in individuals with depression. Emotion, 20(1), 93. DOI: https://doi.org/10.1037/emo0000675

Speed, B. C., Levinson, A. R., Gross, J. J., Kiosses, D. N., \& Hajcak, G. (2017). Emotion regulation to idiographic stimuli: Testing the autobiographical emotion regulation task. Neuropsychologia. DOI: https://doi.org/10.1016/j.neuropsychologia.2017.04.032

Tagliaferri, F., Compagnone, C., Korsic, M., Servadei, F., \& Kraus, J. (2006). A systematic review of brain injury epidemiology in Europe. Acta neurochirurgica, 148(3), 255-268. DOI: https://doi.org/10.1007/s00701-005-0651-y

Troy, A. S., Shallcross, A. J., \& Mauss, I. B. (2013). A person-by-situation approach to emotion regulation: Cognitive reappraisal can either help or hurt, depending on the context. Psychological science, 24(12), 2505-2514. DOI: https://doi.org/10.1177/0956797613496434

Troy, A. S., Wilhelm, F. H., Shallcross, A. J., \& Mauss, I. B. (2010). Seeing the silver lining: cognitive reappraisal ability moderates the relationship between stress and depressive symptoms. Emotion, 10(6), 783. DOI: https://doi.org/10.1037/a0020262

Turnbull, O. H., Evans, C. E., \& Owen, V. (2005). Negative emotions and anosognosia. Cortex, 41(1), 67-75. DOI: https://doi.org/10.1016/S0010-9452(08)70179-5

Twamley, E. W., Palmer, B. W., Jeste, D. V., Taylor, M. J., \& Heaton, R. K. (2006). Transient and executive function working memory in schizophrenia. Schizophrenia research, 87(1-3), 185-190. DOI: https://doi.org/10.1016/j.schres.2006.04.013

van't Wout, M., Chang, L. J., \& Sanfey, A. G. (2010). The influence of emotion regulation on social interactive decision-making. Emotion, 10(6), 815. DOI: http://dx.doi.org/10.1037/a0020069

Webb, T. L., Lindquist, K. A., Jones, K., Avishai, A., \& Sheeran, P. (2018). Situation selection is a particularly effective emotion regulation strategy for people who need help regulating their 
emotions. Cognition and Emotion, 32(2), 231-248. DOI:

https://doi.org/10.1080/02699931.2017.1295922

Weber, H., Loureiro de Assunção, V., Martin, C., Westmeyer, H., \& Geisler, F. C. (2014). Reappraisal inventiveness: The ability to create different reappraisals of critical situations. Cognition \& emotion, 28(2), 345-360.DOI: https://doi.org/10.1080/02699931.2013.832152

Wechsler, D. (2008). Wechsler Adult Intelligence Scale-Fourth Edition (WAIS-IV). San Antonio, TX: The Psychological Corporation.

Williams, C., \& Wood, R. L. (2010). Alexithymia and emotional empathy following traumatic brain injury. Journal of clinical and experimental neuropsychology, 32(3), 259-267. DOI: https://doi.org/10.1080/13803390902976940

Williams, W. H., \& Evans, J. J. (2003). Brain injury and emotion: An overview to a special issue on biopsychosocial approaches in neurorehabilitation. Neuropsychological rehabilitation, 13(1-2), $1-11$.

Zhang, X., Yu, H. W., \& Barrett, L. F. (2014). How does this make you feel? A comparison of four affect induction procedures. Frontiers in psychology, 5, 689. DOI: https://doi.org/10.3389/fpsyg.2014.00689

Figure 1. Figure demonstrating one trial in the impersonal reappraisal task (one IAPS picture out of a set of eight IAPS images).

Figure 2. Figure demonstrating one trial in the personal reappraisal task (one trial in the sad condition out of eight total trials [Sad, Scared, Angry, Neutral, Sad, Scared, Angry, Neutral]). From Rowlands et al., 2019

Figure 3. Graph demonstrating mean reappraisal productivity scores for both the ABI and healthy control group, on the personal and impersonal reappraisal tasks. Significance $* * *<.001$, $* *<.01, *<.05$. Error bars represent $95 \% \mathrm{CI}$.

Figure 4. Graph demonstrating mean reappraisal difficulty (seconds) for both the ABI and healthy control group, on the personal and impersonal reappraisal tasks. Significance $* * *<.001$, $* *<.01, *<.05$. Error bars represent $95 \%$ CI.

Figure 5. Graph demonstrating mean reappraisal effectiveness for both the ABI and healthy control group, on the personal and impersonal reappraisal tasks. Significance $* * *<.001, * *<$ $.01, *<.05$. Error bars represent $95 \%$ CI. 
Figure 6. A proposed model of reappraisal. In the early reappraisal generation phase 1) the automatic appraisal is inhibited (inhibition), 2) the initial meaning and goal of reappraising is kept in mind (working memory), 3) new interpretations are generated (working memory and verbal ability). In the second phase, reappraisal maintenance, 4) the reappraisal is kept in mind and 'shielded' form the initial meaning. The reappraisals' success is monitored and adapted if necessary (monitoring) (5). The process may be facilitated by the available contextual information. In the absence of such information, abstract ideas must be used to facilitate the generation of contesting mental representations (abstract reasoning).

\section{Figure 1.}

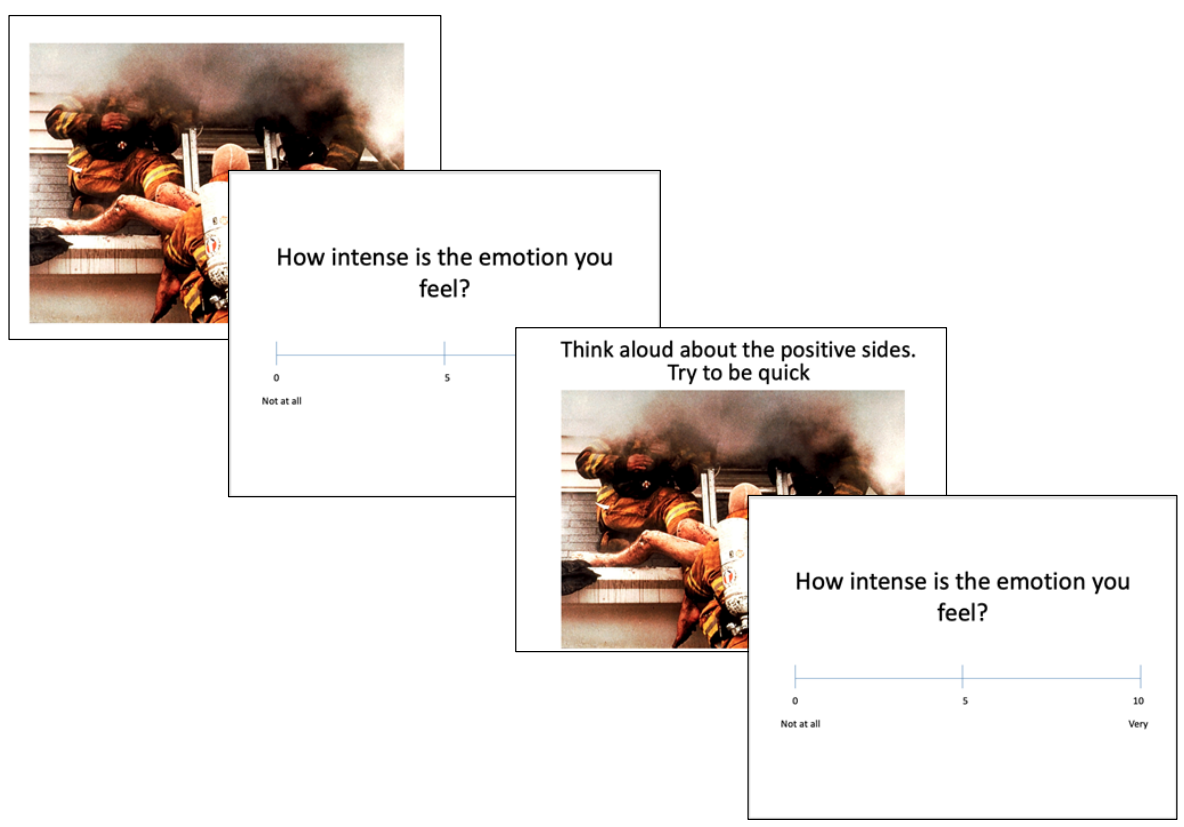


Figure 1. Figure demonstrating one trial in the impersonal reappraisal task (one IAPS picture out of a set of eight IAPS images).

Figure 2.

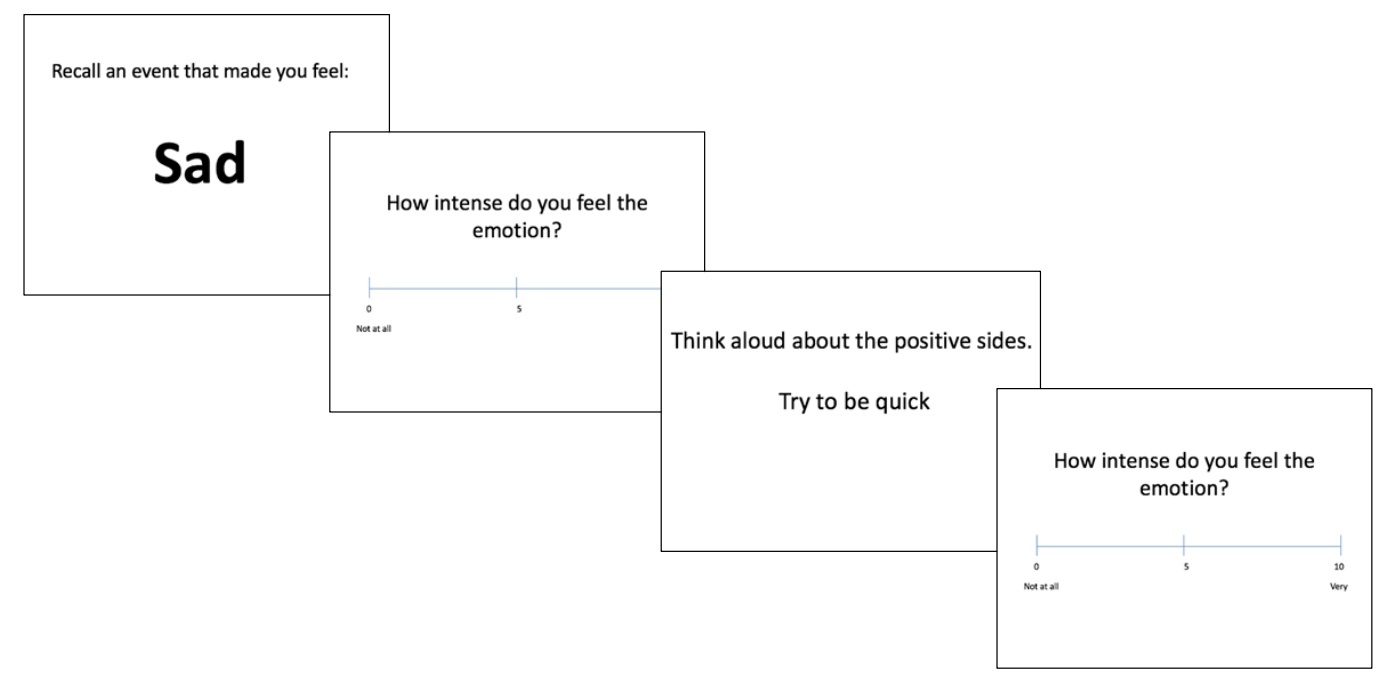


Figure 2. Figure demonstrating one trial in the personal reappraisal task (one trial in the sad condition out of eight total trials [Sad, Scared, Angry, Neutral, Sad, Scared, Angry, Neutral]). From Rowlands et al., 2019

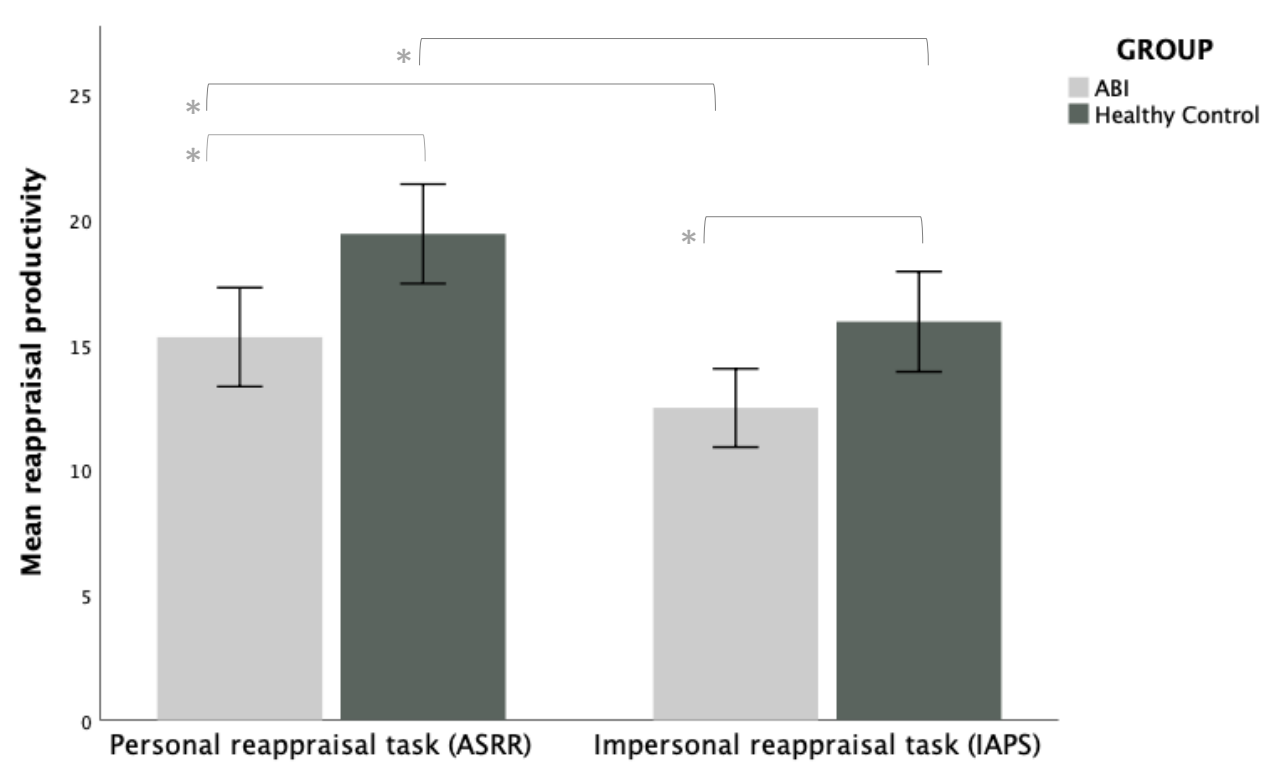

Figure 3. 
Figure 3. Graph demonstrating mean reappraisal productivity scores for both the ABI and healthy control group, on the personal and impersonal reappraisal tasks. Significance $* * *<.001$, $* *<.01, *<.05$. Error bars represent $95 \%$ CI.

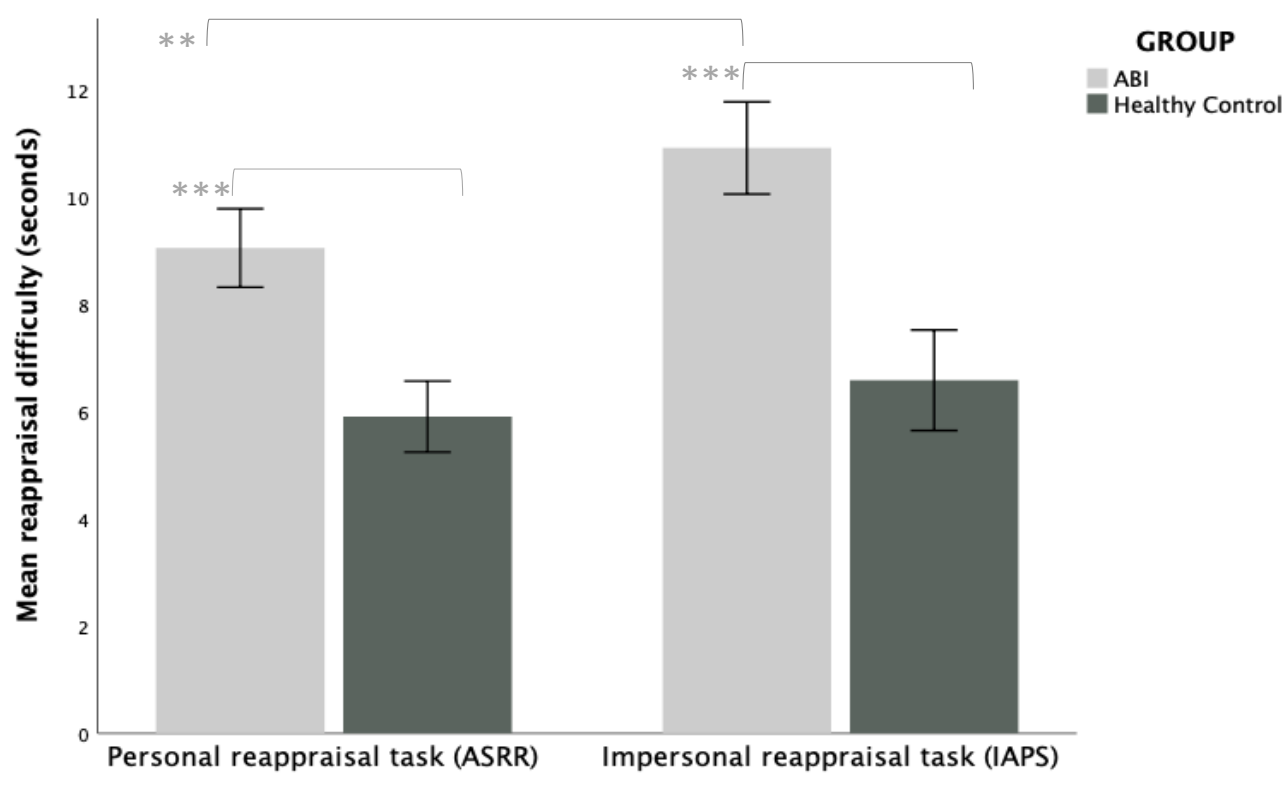

Figure 4. 
Figure 4. Graph demonstrating mean reappraisal difficulty (seconds) for both the ABI and healthy control group, on the personal and impersonal reappraisal tasks. Significance $* * *<.001$, $* *<.01, *<.05$. Error bars represent 95\% CI.

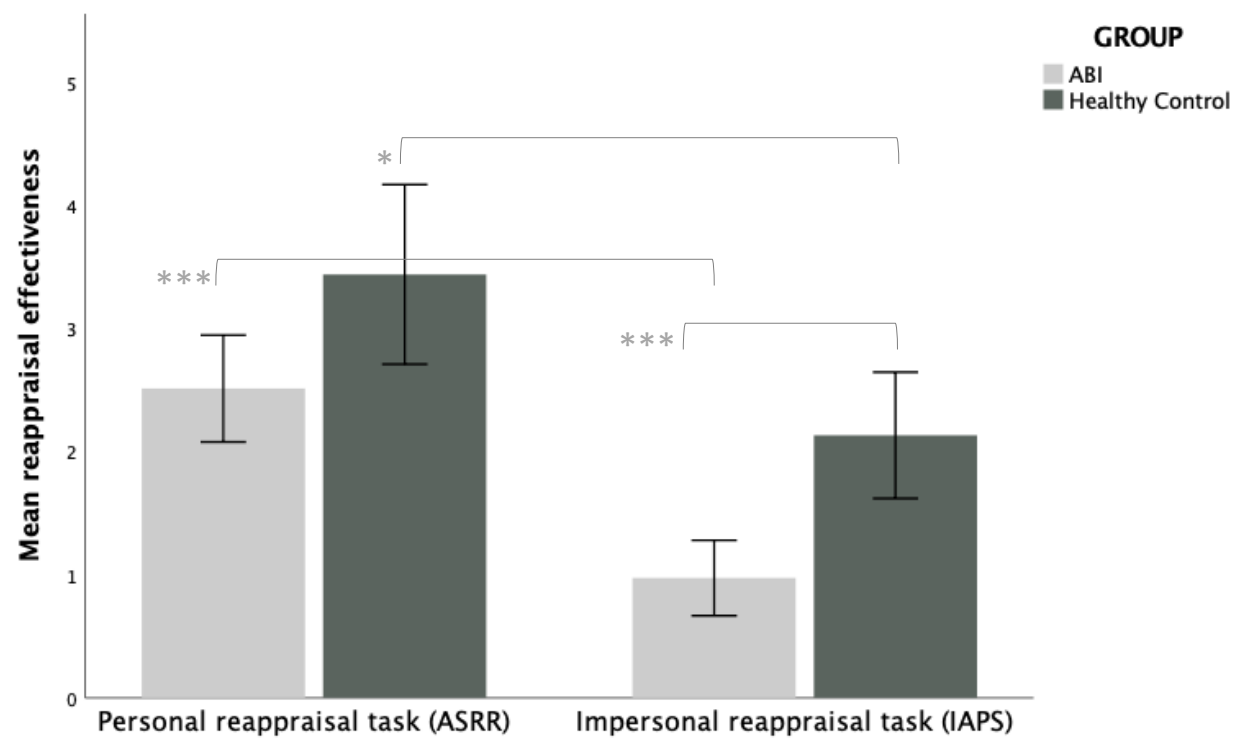

Figure 5. 
Figure 5. Graph demonstrating mean reappraisal effectiveness for both the ABI and healthy control group, on the personal and impersonal reappraisal tasks. Significance $* * *<.001, * *<$ $.01, *<.05$. Error bars represent $95 \% \mathrm{CI}$.

Figure 6. 


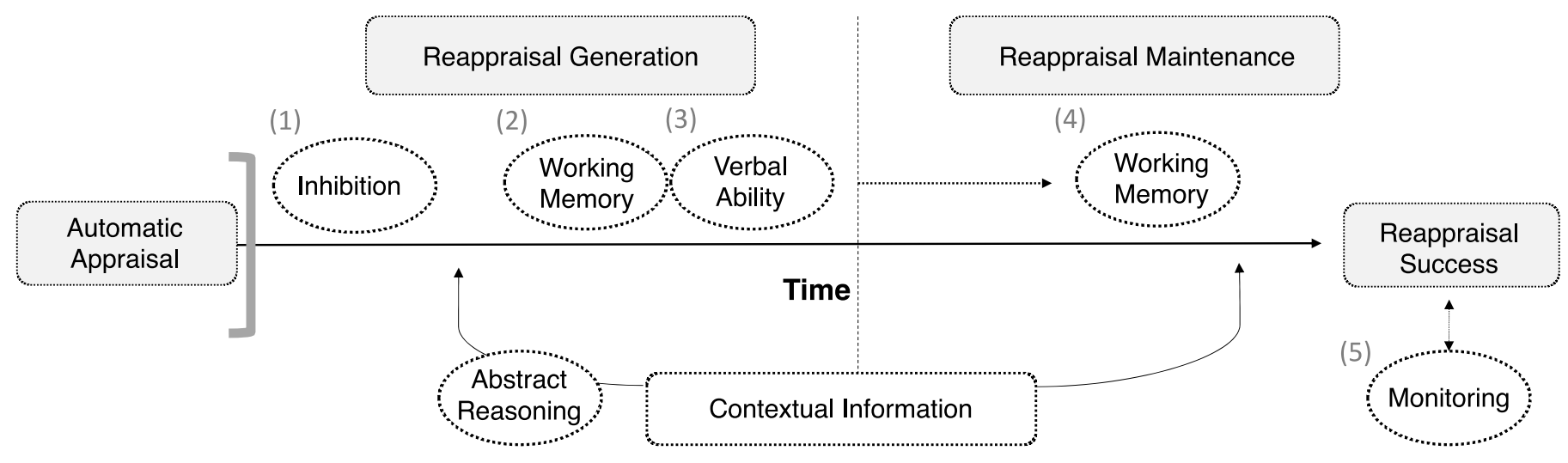

Figure 6. A proposed model of reappraisal. In the early reappraisal generation phase 1) the automatic appraisal is inhibited (inhibition), 2) the initial meaning and goal of reappraising is kept in mind (working memory), 3) new interpretations are generated (working memory and verbal ability). In the second phase, reappraisal maintenance, 4) the reappraisal is kept in mind and 'shielded' form the initial meaning. The reappraisals' success is monitored and adapted if necessary (monitoring) (5). The process may be facilitated by the available contextual information. In the absence of such information, abstract ideas must be used to facilitate the generation of contesting mental representations (abstract reasoning).

Table 1. Demographic and injury information for both the $\mathrm{ABI}$ and $\mathrm{HC}$ group

\begin{tabular}{|c|c|c|c|c|c|}
\hline \multirow[t]{2}{*}{ Group } & Age & Education & \multirow[t]{2}{*}{ Gender } & \multirow{2}{*}{$\begin{array}{l}\text { Years since injury } \\
\mathrm{M}, S D \\
\text { Range }\end{array}$} & \multirow[t]{2}{*}{ ABI Aetiology } \\
\hline & $\begin{array}{l}\mathrm{M} \quad(S D) \\
\text { Range }\end{array}$ & $\begin{array}{l}\mathrm{M} \quad(S D) \\
\text { Range }\end{array}$ & & & \\
\hline \multirow[t]{2}{*}{ ABI } & $46 \quad(11.44)$ & $13(3.21)$ & $\mathrm{M}(n=38)$ & & $\begin{array}{l}\text { CVA }(n=20) \\
\text { TBI }(n=28)\end{array}$ \\
\hline & $22-67$ & $10-20$ & $\mathrm{~F}(n=17)$ & 9 months -32 & $\begin{array}{l}\text { Encephalitis }(n=2) \\
\text { Tumour removal }(n=1) \\
\text { Hypoxia }(n=2) \\
\text { Radiation }(n=1) \\
\text { Hydrocephalus }(n=1)\end{array}$ \\
\hline \multirow[t]{2}{*}{$\mathrm{HC}$} & $46 \quad(10.90)$ & 12 (1.77) & $\mathrm{M}(n=21)$ & & \\
\hline & $32-69$ & $10-17$ & $\mathrm{~F}(n=14)$ & & \\
\hline Sig. & $\begin{array}{l}t=-1.60 \\
p=.114\end{array}$ & $\begin{array}{l}t=1.23 \\
p=.221\end{array}$ & & & \\
\hline
\end{tabular}


Education $=$ years $; C V A=$ cerebrovascular accident, $T B I=$ traumatic brain injury. There were no significant differences in age or education between groups. For the ABI group $69 \%$ of the sample were male and $31 \%$ are female, and for the HC group $60 \%$ of the sample were male and $40 \%$ female. 
Table 2. Descriptive statistics of performance on all measures

\begin{tabular}{|c|c|c|c|c|c|}
\hline & Group & $M$ & $S D$ & Mdn & $\begin{array}{c}\text { Sig. } \\
\text { difference } \\
\text { (ABI vs } \\
\text { HC) } \\
\end{array}$ \\
\hline $\begin{array}{l}\text { Impersonal Reappraisal } \\
\text { Task }\end{array}$ & & & & & \\
\hline Reappraisal productivity & $\begin{array}{c}\mathrm{ABI} \\
\mathrm{HC}\end{array}$ & $\begin{array}{l}12.50 \\
15.94\end{array}$ & $\begin{array}{l}5.80 \\
5.84\end{array}$ & $\begin{array}{l}11.00 \\
15.00\end{array}$ & $.032 *$ \\
\hline $\begin{array}{l}\text { Reappraisal difficulty } \\
\text { (seconds) }\end{array}$ & $\begin{array}{c}\mathrm{ABI} \\
\mathrm{HC}\end{array}$ & $\begin{array}{l}10.92 \\
6.59\end{array}$ & $\begin{array}{l}3.18 \\
2.73\end{array}$ & $\begin{array}{l}10.89 \\
6.00\end{array}$ & $<.001 * * *$ \\
\hline Reappraisal effectiveness & $\begin{array}{l}\mathrm{ABI} \\
\mathrm{HC}\end{array}$ & $\begin{array}{l}0.97 \\
2.13\end{array}$ & $\begin{array}{l}1.13 \\
1.49\end{array}$ & $\begin{array}{l}0.75 \\
2.00\end{array}$ & $<.001 * * *$ \\
\hline $\begin{array}{l}\text { Personal } \\
\text { Reappraisal Task }\end{array}$ & & & & & \\
\hline Reappraisal productivity & $\begin{array}{l}\mathrm{ABI} \\
\mathrm{HC}\end{array}$ & $\begin{array}{l}15.33 \\
19.46\end{array}$ & $\begin{array}{l}7.32 \\
5.78\end{array}$ & $\begin{array}{l}13.00 \\
21.00\end{array}$ & $.021 *$ \\
\hline $\begin{array}{l}\text { Reappraisal difficulty } \\
\text { (seconds) }\end{array}$ & $\begin{array}{l}\mathrm{ABI} \\
\mathrm{HC}\end{array}$ & $\begin{array}{l}9.05 \\
5.91\end{array}$ & $\begin{array}{l}2.71 \\
1.93\end{array}$ & $\begin{array}{l}9.00 \\
6.00\end{array}$ & $<.001 * * *$ \\
\hline Reappraisal effectiveness & $\begin{array}{l}\mathrm{ABI} \\
\mathrm{HC}\end{array}$ & $\begin{array}{l}2.51 \\
3.44\end{array}$ & $\begin{array}{l}1.61 \\
2.12\end{array}$ & $\begin{array}{l}2.25 \\
2.75\end{array}$ & .110 \\
\hline $\begin{array}{l}\text { Baseline Emotional } \\
\text { Intensity Ratings } \\
\text { (covariate) }\end{array}$ & & & & & \\
\hline Impersonal task & $\begin{array}{l}\mathrm{ABI} \\
\mathrm{HC}\end{array}$ & $\begin{array}{l}5.85 \\
6.91\end{array}$ & $\begin{array}{l}2.40 \\
1.80\end{array}$ & $\begin{array}{l}6.38 \\
6.88\end{array}$ & $\begin{aligned} Z & =-1.80(p \\
& =.071)\end{aligned}$ \\
\hline Personal task & $\begin{array}{l}\mathrm{ABI} \\
\mathrm{HC}\end{array}$ & $\begin{array}{l}6.50 \\
7.40\end{array}$ & $\begin{array}{l}2.30 \\
1.34\end{array}$ & $\begin{array}{l}6.87 \\
7.25\end{array}$ & $\begin{array}{l}Z=-1.70 \\
(p=.090)\end{array}$ \\
\hline $\begin{array}{l}\text { Sig Diff } \\
\text { Between tasks }\end{array}$ & $\mathrm{ABI}$ & & & & $\begin{array}{l}Z=-2.57 \\
(p=.010)\end{array}$ \\
\hline & $\mathrm{HC}$ & & & & $\begin{array}{l}Z=-2.22 \\
(p=.027)\end{array}$ \\
\hline $\begin{array}{l}\text { Working Memory } \\
\text { (Digits WAIS) }\end{array}$ & $\begin{array}{l}\mathrm{ABI} \\
\mathrm{HC}\end{array}$ & $\begin{array}{c}7.55 \\
10.11\end{array}$ & $\begin{array}{l}2.67 \\
1.86\end{array}$ & $\begin{array}{c}8.00 \\
10.00\end{array}$ & $<.001 * * *$ \\
\hline $\begin{array}{l}\text { Verbal Ability } \\
\text { (Letter Fluency D-KEFS) }\end{array}$ & $\begin{array}{l}\mathrm{ABI} \\
\mathrm{HC}\end{array}$ & $\begin{array}{l}7.04 \\
9.57\end{array}$ & $\begin{array}{l}3.43 \\
3.18\end{array}$ & $\begin{array}{l}7.00 \\
9.00\end{array}$ & $<.001$ \\
\hline $\begin{array}{l}\text { Inhibition } \\
\text { (Hayling) }\end{array}$ & $\begin{array}{l}\mathrm{ABI} \\
\mathrm{HC}\end{array}$ & $\begin{array}{l}4.82 \\
5.92\end{array}$ & $\begin{array}{l}1.81 \\
1.13\end{array}$ & $\begin{array}{l}6.00 \\
6.00\end{array}$ & $.001 * *$ \\
\hline
\end{tabular}




\begin{tabular}{lccccc}
\hline Self-report reappraisal & ABI & 23.78 & 7.14 & 24.00 & $<.001^{* * *}$ \\
(ERQ-CA) & HC & 30.23 & 7.00 & 31.00 & \\
& & & & & \\
\hline
\end{tabular}

Significance $* * *<.001, * *<.01, *<.05$. 
Table 3. Results of robust multiple linear regression models for the personal reappraisal task

\begin{tabular}{|c|c|c|c|c|c|c|}
\hline Model & $\mathrm{R}^{2}$ & $F$ & $p$ (sig.) & $\begin{array}{l}\beta \text { coefficients } \\
\text { (bootstrapped) }\end{array}$ & $p$ (sig.) & $95 \% \mathrm{CIs}$ \\
\hline \multicolumn{7}{|l|}{ ABI Group } \\
\hline \multicolumn{7}{|l|}{$\begin{array}{c}\text { Personal Reappraisal } \\
\text { Task }\end{array}$} \\
\hline $\begin{array}{l}\text { Reappraisal } \\
\text { Productivity }\end{array}$ & .05 & 2.10 & .718 & & & \\
\hline Working Memory & & & & 0.38 & .177 & $-0.48-1.15$ \\
\hline Verbal Ability & & & & 0.29 & 241 & $-0.42-1.13$ \\
\hline Inhibition & & & & -0.42 & .302 & $1.91-1.05$ \\
\hline $\begin{array}{r}\text { Baseline intensity } \\
\text { (covariate) }\end{array}$ & & & & 0.21 & .271 & $-0.63-0.94$ \\
\hline $\begin{array}{l}\text { Reappraisal } \\
\text { Difficulty }\end{array}$ & .13 & 6.47 & .166 & & & \\
\hline Working Memory & & & & -0.25 & $.041^{*}$ & $-0.54-0.04$ \\
\hline Verbal Ability & & & & -0.07 & 191 & $-0.26-0.11$ \\
\hline Inhibition & & & & -0.17 & .399 & $-0.68-0.43$ \\
\hline $\begin{array}{r}\text { Baseline intensity } \\
\text { (covariate) }\end{array}$ & & & & -0.26 & .137 & $-0.75-0.19$ \\
\hline $\begin{array}{l}\text { Reappraisal } \\
\text { Effectiveness }\end{array}$ & .22 & 14.35 & $.006 * *$ & & & \\
\hline Working Memory & & & & -1.71 & .420 & $-0.19-0.14$ \\
\hline Verbal Ability & & & & 3.74 & .242 & $-0.06-0.14$ \\
\hline Inhibition & & & & 2.44 & $.037^{*}$ & $-0.01-0.51$ \\
\hline $\begin{array}{r}\text { Baseline intensity } \\
\text { (covariate) }\end{array}$ & & & & 2.46 & $.007 * *$ & $0.07-0.42$ \\
\hline
\end{tabular}

\section{(ABI group).}

$* * *$ Significance $<.001, * *$ Significance $<.01, *<.05$ 
Table 4. Results of robust multiple linear regression models for the impersonal reappraisal task (ABI group)

\begin{tabular}{|c|c|c|c|c|c|c|}
\hline Model & $\mathrm{R}^{2}$ & $F$ & $p$ (sig.) & $\begin{array}{l}\beta \text { coefficients } \\
\text { (bootstrapped) }\end{array}$ & $p$ (sig.) & $95 \% \mathrm{CIs}$ \\
\hline \multicolumn{7}{|l|}{ ABI Group } \\
\hline \multicolumn{7}{|l|}{$\begin{array}{c}\text { Impersonal } \\
\text { Reappraisal Task }\end{array}$} \\
\hline $\begin{array}{l}\text { Reappraisal } \\
\text { Productivity }\end{array}$ & .18 & 9.21 & .056 & & & \\
\hline Working Memory & & & & 0.52 & $.034^{*}$ & $-0.05-1.07$ \\
\hline Verbal Ability & & & & 0.21 & .204 & $-0.30-0.74$ \\
\hline Inhibition & & & & 0.10 & .412 & $-0.93-1.13$ \\
\hline $\begin{array}{r}\text { Baseline intensity } \\
\text { (covariate) }\end{array}$ & & & & 0.71 & $.005^{* *}$ & $0.18-1.16$ \\
\hline $\begin{array}{l}\text { Reappraisal } \\
\text { Difficulty }\end{array}$ & .16 & 7.74 & .102 & & & \\
\hline Working Memory & & & & -0.13 & .192 & $-0.43-0.16$ \\
\hline Verbal Ability & & & & 0.02 & .408 & $-0.19-0.23$ \\
\hline Inhibition & & & & -0.56 & $.020^{*}$ & $-1.11--0.02$ \\
\hline $\begin{array}{r}\text { Baseline intensity } \\
\text { (covariate) }\end{array}$ & & & & -0.08 & .323 & $-0.48-0.27$ \\
\hline $\begin{array}{l}\text { Reappraisal } \\
\text { Effectiveness }\end{array}$ & .15 & 8.51 & .074 & & & \\
\hline Working Memory & & & & 0.01 & .483 & $-0.15-0.15$ \\
\hline Verbal Ability & & & & -0.04 & .211 & $-0.16-0.07$ \\
\hline Inhibition & & & & 0.18 & $.041 *$ & $-0.02-0.40$ \\
\hline $\begin{array}{r}\text { Baseline intensity } \\
\text { (covariate) }\end{array}$ & & & & 0.09 & $.035^{*}$ & $-0.01-0.17$ \\
\hline
\end{tabular}

$* * *$ Significance $<.001, * *$ Significance $<.01, *<.05$ 
Table 5. Results of robust multiple linear regression models for the personal reappraisal task (HC group)

\begin{tabular}{|c|c|c|c|c|c|c|}
\hline Model & $\mathrm{R}^{2}$ & $F$ & $p$ (sig.) & $\begin{array}{l}\beta \text { coefficients } \\
\text { (bootstrapped) }\end{array}$ & $p$ (sig.) & $95 \%$ CIs \\
\hline $\begin{array}{l}\text { Healthy Control } \\
\text { Group }\end{array}$ & & & & & & \\
\hline $\begin{array}{c}\text { Personal } \\
\text { Reappraisal Task }\end{array}$ & & & & & & \\
\hline $\begin{array}{l}\text { Reappraisal } \\
\text { Productivity }\end{array}$ & .15 & .12 & .538 & & & \\
\hline Working Memory & & & & 0.27 & .388 & $-1.52-2.18$ \\
\hline Verbal Ability & & & & -0.37 & .164 & $-1.19-0.34$ \\
\hline Inhibition & & & & 0.23 & .367 & $-1.89-2.87$ \\
\hline $\begin{array}{r}\text { Baseline intensity } \\
\text { (covariate) }\end{array}$ & & & & 1.29 & .191 & $-1.52-3.86$ \\
\hline $\begin{array}{l}\text { Reappraisal } \\
\text { Difficulty }\end{array}$ & .28 & 11.69 & $.019^{*}$ & & & \\
\hline Working Memory & & & & -0.07 & .399 & $-0.53-0.34$ \\
\hline Verbal Ability & & & & 0.09 & .208 & $-0.11-0.30$ \\
\hline Inhibition & & & & -0.74 & $.004 * *$ & $-1.27--0.18$ \\
\hline $\begin{array}{r}\text { Baseline intensity } \\
\text { (covariate) }\end{array}$ & & & & 0.12 & .297 & $-0.40-0.54$ \\
\hline $\begin{array}{l}\text { Reappraisal } \\
\text { Effectiveness }\end{array}$ & .46 & 15.96 & $.003 * *$ & & & \\
\hline Working Memory & & & & -0.04 & .438 & $-0.37-0.34$ \\
\hline Verbal Ability & & & & -0.15 & .087 & $-0.38-0.11$ \\
\hline Inhibition & & & & 0.13 & .397 & $-0.61-0.94$ \\
\hline $\begin{array}{r}\text { Baseline intensity } \\
\text { (covariate) }\end{array}$ & & & & 0.90 & $.002 * *$ & $0.30-1.96$ \\
\hline
\end{tabular}

$* * *$ Significance $<.001, * *$ Significance $<.01, *<.05$ 
Table 6. Results of robust multiple linear regression models for the impersonal reappraisal task

\begin{tabular}{|c|c|c|c|c|c|c|}
\hline Model & $\mathrm{R}^{2}$ & $F$ & $p$ (sig.) & $\begin{array}{l}\beta \text { coefficients } \\
\text { (bootstrapped) }\end{array}$ & $p$ (sig.) & $95 \%$ CIs \\
\hline \multicolumn{7}{|l|}{$\begin{array}{l}\text { Healthy Control } \\
\text { Group }\end{array}$} \\
\hline \multicolumn{7}{|l|}{$\begin{array}{c}\text { Impersonal } \\
\text { Reappraisal Task }\end{array}$} \\
\hline $\begin{array}{l}\text { Reappraisal } \\
\text { Productivity }\end{array}$ & .04 & 1.24 & .872 & & & \\
\hline Working Memory & & & & -0.51 & .165 & $-1.83-0.80$ \\
\hline Verbal Ability & & & & -0.03 & .447 & $-0.65-0.63$ \\
\hline Inhibition & & & & 0.47 & .301 & $-1.56-2.05$ \\
\hline $\begin{array}{r}\text { Baseline intensity } \\
\text { (covariate) }\end{array}$ & & & & -0.12 & .403 & $-1.50-1.07$ \\
\hline $\begin{array}{l}\text { Reappraisal } \\
\text { Difficulty }\end{array}$ & .15 & 1.81 & .771 & & & \\
\hline Working Memory & & & & -0.05 & .456 & $-0.77-0.57$ \\
\hline Verbal Ability & & & & 0.01 & .438 & $-0.32-0.35$ \\
\hline Inhibition & & & & -0.86 & .093 & $-2.35-0.37$ \\
\hline $\begin{array}{r}\text { Baseline intensity } \\
\text { (covariate) }\end{array}$ & & & & 0.22 & .188 & $-0.31-0.80$ \\
\hline $\begin{array}{l}\text { Reappraisal } \\
\text { Effectiveness }\end{array}$ & .21 & 8.22 & .084 & & & \\
\hline Working Memory & & & & -0.16 & .153 & $-0.50-0.21$ \\
\hline Verbal Ability & & & & 0.02 & .363 & $-0.11-0.21$ \\
\hline Inhibition & & & & -0.14 & .337 & $-0.71-0.41$ \\
\hline $\begin{array}{r}\text { Baseline intensity } \\
\text { (covariate) }\end{array}$ & & & & 0.33 & $.030 *$ & $-0.02-0.63$ \\
\hline
\end{tabular}

$* * *$ Significance $<.001, * *$ Significance $<.01, *<.05$ 


\begin{tabular}{lc}
\hline & ABI Group \\
\hline Task & Correlation coefficients $(p$ value) \\
\hline Personal reappraisal task & $.41(.002)^{* *}$ \\
\hline Reappraisal Productivity & $-.34(.011)^{* *}$ \\
Reappraisal Difficulty (seconds) & $.559(<.001)^{* * *}$ \\
Reappraisal Effectiveness & \\
\hline Impersonal reappraisal Task & $.30(.026)^{*}$ \\
\hline Reappraisal Productivity & $-.14(.321)$ \\
Reappraisal Difficulty (seconds) & $.09(.507)$ \\
Reappraisal Effectiveness & HC Group \\
\hline Task & Correlation coefficients $(p$ value $)$ \\
\hline Personal Reappraisal Task & ERQ-CA \\
\hline Reappraisal Productivity & $.10(.560)$ \\
Reappraisal Difficulty (seconds) & $-.02(.901)$ \\
Reappraisal Effectiveness & $.16(.371)$ \\
\hline Impersonal reappraisal Task & $-.19(.288)$ \\
\hline Reappraisal Productivity & $-.10(.588)$ \\
Reappraisal Difficulty (seconds) & \\
Reappraisal Effectiveness & \\
\hline
\end{tabular}

Tab

le 7.

Corr

elati

ons

bet

wee

n

task

perf

orm

ance

Signi

fican

ce

$* * *<$

.001 ,

$* *<$

$.01, *$

$<.05$ 


\section{Appendix A - Personal reappraisal and Impersonal Reappraisal Task Instructions Personal reappraisal task (IAPS stimuli)}

Introduction. The task was introduced as follows "Sometimes people try to make themselves feel better by looking on the bright side of things. You will see a series of pictures on the screen. Spend a little bit of time looking at the picture. You will then rate how intense your emotional response to the picture on a 0 to 10 scale, with 10 being most intense. The next step is to think of as many positive sides of what you are seeing as you can, as quickly as you can. After thinking of the positive sides, rate how you feel again on the same 0 to 10 scale".

As pictures which result in lower emotional intensity ratings can be up-regulated into positive this was explained in more detail: "Low scores on the scale mean less intensely and high scores mean more intense. However, if your emotional response to an image is low, you can upregulate to positive. That is, you can think of higher numbers on the scale to mean that you feel more positive about it. Do you understand the difference?" Before we start we have time to practice".

Practice. Patients were then trained on the task using two IAPS pictures. Following this, participants were shown the 0-10 scale, and the description of the scale was repeated again. They were then required to think of reappraisals when prompted by the written cue "Think of the positive sides. Try to be quick", before examples of possible reappraisals were provided. For Set A, one of the practice pictures was 'Truck' which included a vehicle stuck in mud with people pushing it, and example reappraisals are 'People are helping each other' and 'they will get out 
without damage'. The emotion intensity scale was shown and explained again. If the participant did not understand the task, the practice procedure was repeated, until the participant was satisfied that they understood what was required during the task.

Testing. Participants engaged with each picture for as long as they felt necessary to grasp its content. Their responses to the reappraising cue ("Think of the positive sides. Try to be quick") were timed and audio-recorded. These recordings were later transcribed verbatim. If participants struggled to think of reappraisals after two minutes, they were prompted as per Salas et al., 2013 (e.g. 'Could you please try to think of the positive sides of this?').

\section{Impersonal Reappraisal Task (autobiographical recall stimuli)}

Introduction. The task was introduced as follows "Sometimes people try to make themselves feel better by looking on the bright side of things. You will see an emotion word on the screen, it will be either sad, scared, angry, or neutral. When you see each word, try to recall an event in your life that caused you to feel that emotion. Try to be very detailed about the way you feel. Following this, you will rate how intensely you feel that emotion now, upon describing the event, on a 0 to 10 scale, with 10 being most intense. The next step is to think of as many positive sides of that situation as you can, as quickly as you can. After thinking of the positive sides, rate how you feel again on the same 0 to 10 scale".

As the "neutral" condition involves the up-regulation of emotion from neutral to happy, this was explained in more detail: "With sad, scared, and angry, low scores on the scale mean less intensely and high scores mean more intense. However, with neutral, the more neutral it is, the lower the score, and high scores mean happy. Do you understand the difference?" Before we start we have time to practice". 
Practice. Patients were then trained on the task using an "angry", and then a "neutral" practice condition, with examples of two stories: Having an argument for the "angry" condition, and watching television for the "neutral" condition. Following this, participants were shown the $0-10$ scale, and the description of the scale was repeated again. They were then required to think of reappraisals when prompted by the written cue "Think of the positive sides. Try to be quick", before examples of possible reappraisals were provided. For the "neutral" condition the example reappraisals were "I was watching television with family, which I am lucky to have and spend time with" and "It was nice to have an evening to relax". The example reappraisals for the “angry" condition were: "We don't argue that often" and "Because of this we've talked about ways we can communicate better in future". The emotion intensity scale was shown and explained again. If the participant did not understand the task, the practice procedure was repeated, until the participant was satisfied that they understood what was required during the task.

Testing. Participants were informed that they have a maximum of three minutes to describe their stories (as per Salas et al., 2015), but they could use more time if needed. Their responses to the reappraising cue ("Think of the positive sides. Try to be quick") were timed and audio-recorded. These recordings are later transcribed verbatim. If participants struggled to think of stories, they were prompted with generic stories, for example "Some people would say they were sad when they lost a pet or family member", "Some people would say they were angry when they came across someone being rude or disrespectful", "Some would say they were scared when they feared for their or their family's safety or well-being", "Some would say they were neutral when going for a walk". Previous work using an ASR task, however, shows that brain-injured patients are able to recall emotional events (Salas et al., 2015, Turnbull et al., 
2005). In line with this, all patients were able to recall stories, though some required additional

prompting during the "neutral" condition, which consisted of asking the participant what they did on the days leading up to the testing session.

\section{Appendix 1 - Details of IAPS sets}

Details of IAPS sets

Set $\mathrm{A}-$ Mean Valence $=3.10(S D=0.84)$, Mean Arousal $=5.25(S D=0.75)$

Practice: 2683 WAR

Practice: 9041 SCARED CHILD

2745 SHOPLIFTING

2053 BABY

2141 GRIEVING FEMALE

5971 TORNADO

2480 ELDERLY MAN

9530 BOYS

9622 JET

9920 CAR ACCIDENT

Set $B$ - Mean Valence $=3.00(S D=0.80)$, Mean Arousal $=4.91(S D=0.85)$

Practice: 9495 FIRE

Practice: 2900 CRYING BOY

9220 CEMETERY

2751 DRUNK DRIVING

9404 SOLDIERS

9341 POLLUTION

9611 PLANE CRASH

9921 FIRE

9471 BURNT BUILDING

2520 ELDERLY MAN

Set $\mathrm{C}-$ Mean Valence $=2.70(S D=0.70)$, Mean Arousal $=5.45(S D=0.77)$

Practice: 9435 ACCIDENT 
Practice: 9280 SMOKE

9910 CAR ACCIDENT

2205 HOSPITAL

3181 BATTERED FEMALE

3220 HOSPITAL

9621 SHIP

8485 FIRE

6838 POLICE

2752 ALCOHOLIC

Set D - Mean Valence $=3.00(S D=0.61)$, Mean Arousal $=5.35(S D=0.69)$

Practice: 2272 LONELY BOY

Practice: 9250 WAR VICTIM

6834 POLICE

9230 OIL FIRE

9520 KIDS

9470 RUINS

2661 BABY

9911 CAR ACCIDENT

2455 SAD GIRLS

2750 BUM

Set $\mathrm{E}$ - Mean Valence $=2.80(S D=0.70)$, Mean Arousal $=5.68(S D=0.60)$

9913 TRUCK

9046 FAMILY

2691 RIOT

3350 INFANT

9342 POLLUTION

9911 CAR ACCIDENT

6836 POLICE

3230 DYING MAN

9050 PLANE CRASH

5972 TORNADO

Appendix C- Example transcriptions of participants' reappraisals on both tasks 


\begin{abstract}
ABI patient 1
Personal Task (Story Recall: Scared when they were unable to provide for family following brain injury)

Reappraisals: Positive sides, like my wife says, I have recovered, I've come back from dire consequences. I suppose, I've recovered from something I don't understand, got back on the bike, and got back to work. I've had the great help of [Psychologist's name] at the service. My friends have been amazing and my family, and the love shown to me by people [**Exhales loudly. Eyes tear up**], I swear to god, one of the things that helped me recover is looking back at messages and the love shown to me and my situation [**voice breaks from emotion**]. And you can have bad times in your life when you think the world is against you, but you learn through adversity that they are not, and that is a great feeling, you think my god, there's some good people out there and that is truly great. Faith in humanity definitely. I feel good now. Impersonal task (Sick Baby picture) Reappraisals: Oh god... oh god I feel that... makes me feel really... just hope that there's a positive outcome... it's an odd picture... Is it a new born baby...or is it? It's odd...There's nothing else positive.
\end{abstract}

\title{
ABI patient 2
}

Personal Task (Story Recall: Sad when family dog was sick)

Reappraisals: We actually managed to go to RSPCA vets who helped, and they were cheaper.

We definitely got a better vet, who gave her a really good check over and the right medication. The pill was cheaper than the one at the normal vets, and we left feeling like we hadn't been ripped off. We gave them extra money as a good will gesture because, they are a charity and needed the money, and I felt pretty good having done that. 


\section{Impersonal task (Sick man picture)}

Reappraisals: I don't know enough information about it... The guy seems pretty ill. I don't know whether he is... I don't know if he is going to survive or pass away, so I don't know. It's not a very pleasant picture.

\section{ABI patient 3}

Personal Task (Story Recall: Neutral when going Kayaking)

Reappraisals: The positive sides is the company I have when I go, the people who are out on the water with me, from all sorts of backgrounds, young and old, fantastic company. When I'm out there I forget about everything that's going on in my life outside the kayaking. The surrounding is fantastic, the views form the lake is stunning. It enhances my life really, it's superb, one of the best things I've ever done was getting in to it. And of course, it keeps me fit. The emotions take

over, it gives me things to talk about, and it's all I think about, comparing this week's views with the previous week. Now I can't really measure how much more positive I feel, it consumes me.

Impersonal task (Lonely man picture)

Reappraisals: I don't really have any personal attachment to the picture...if I did it would be different...but I can empathise with this chap looking out the window. Nothing much in the house, suggests poverty to me...the positive is that he has a view out of his window, and maybe he is waiting for someone to come and visit...that's it really.

\section{HC participant}

Personal Task (Story Recall: Having to take family dog for euthanasia) 
Reappraisals: Positive side is just how lucky I am to have had her in my life and all the love and fun she brought. I have the happy memories to cheer me up when I'm sad about it. And I guess...knowing that I did the right thing by her, and that she is now out of her pain, makes me feel better. All the family were there with her at the time giving her treats, so she was as comfortable as she could have been. And she had a great life with us."

Impersonal task (Boys picture)

Reappraisals: Oh... Well, the kids have each other. They are probably just playing in the dirt, having fun, being kids. They don't look like they are malnourished or anything like that. 